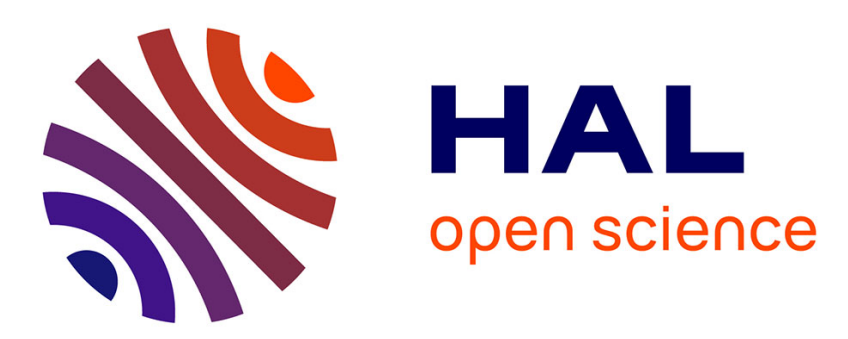

\title{
Conformational analysis of new 14-membered ring diketal dilactam macrocycles: molecular mechanics, liquid and solid state NMR studies
}

\author{
Denise Dugat, Ag Valade, Bruno Combourieu, J. Guyot
}

\section{To cite this version:}

Denise Dugat, Ag Valade, Bruno Combourieu, J. Guyot. Conformational analysis of new 14-membered ring diketal dilactam macrocycles: molecular mechanics, liquid and solid state NMR studies. Tetrahedron, 2005, 61, pp.5641-5653. 10.1016/j.tet.2005.03.073 . hal-00125729

\author{
HAL Id: hal-00125729 \\ https://hal.science/hal-00125729
}

Submitted on 5 Mar 2007

HAL is a multi-disciplinary open access archive for the deposit and dissemination of scientific research documents, whether they are published or not. The documents may come from teaching and research institutions in France or abroad, or from public or private research centers.
L'archive ouverte pluridisciplinaire $\mathbf{H A L}$, est destinée au dépôt et à la diffusion de documents scientifiques de niveau recherche, publiés ou non, émanant des établissements d'enseignement et de recherche français ou étrangers, des laboratoires publics ou privés. 


\title{
Conformational analysis of new 14-membered ring diketal dilactam macrocycles: molecular mechanics, liquid and solid state NMR studies
}

\author{
Denise Dugat, * Anne-Gaëlle Valade, Bruno Combourieu and Jacques Guyot \\ Synthèse et Etude de Systèmes à Intérêt Biologique, UMR CNRS 6504, Université Blaise Pascal de Clermont-Ferrand, \\ 63177 Aubière, France
}

\begin{abstract}
1. Introduction
In the last four decades, conformational analysis of macrocyclic compounds has attracted increasing interest, partly because of the insight it brings on the physical and chemical properties of these systems.

For some years we have been interested in the synthesis $^{1}$ and in cationic recognition properties $^{2}$ of new diversely substituted 14-membered ring compounds bearing diketal and dilactam functions (Scheme 1). The conformational preferences of these macrocycles according to the nature of their substituents should help to account for the differences observed in their binding abilities. The complexity of the molecules, due to the presence of two different functions and of various substituents, prompted us first to search the literature for proposed shapes for these structures, beginning with the
\end{abstract}

Keywords: Diketal dilactam macrocycles; Conformational analysis; Computational studies; Liquid and solid state NMR.

* Corresponding author. Tel.: +33473407127; fax: +33473407717; e-mail: denise.dugat@chimie.univ-bpclermont.fr

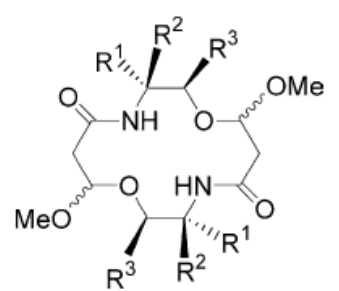

Scheme 1 .

unsubstituted 14-membered ring cycloalkane, cyclotetradecane.

The conformation of cyclotetradecane was thoroughly investigated using, successively, qualitative analysis, ${ }^{3}$ semi-quantitative enthalpy calculations, ${ }^{4}$ low temperature NMR, ${ }^{5} \mathrm{X}$-ray diffraction, ${ }^{6}$ solid state ${ }^{13} \mathrm{C}$ NMR, ${ }^{7}$ molecular mechanics methods ${ }^{8}$ and vibrational spectroscopy. ${ }^{9}$ These studies show that $\mathrm{c}-\mathrm{C}_{14} \mathrm{H}_{28}$ occurs in the solid state as an ordered crystalline phase with a single conformation, ${ }^{6,7}$ but in the liquid state the cycloalkane ring loses its conformational homogeneity and occurs in several conformations, among which the crystal conformation is largely 


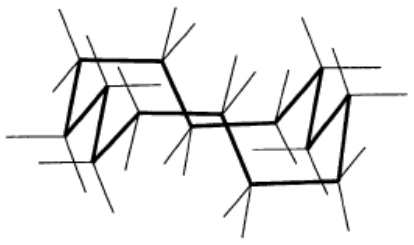

(A) [3434]

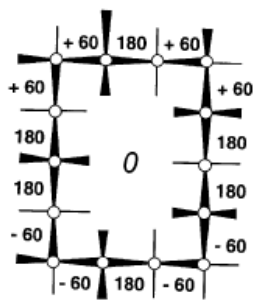

(A) [3434]

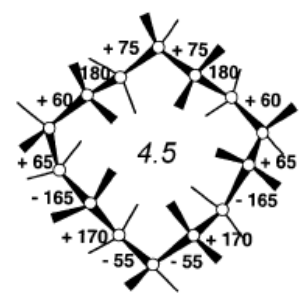

(B) $[3344]$

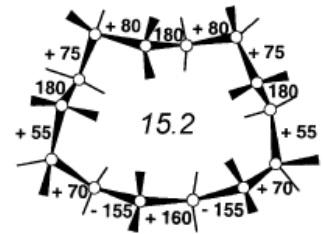

(B) [3335]
Figure 1. Representations of cyclotetradecane: (A) Side view and top view of the [3434] rectangular conformer, ${ }^{3 a, 4}$ (B) Top views of the [3344] and [3335] quadrangular conformers. ${ }^{3 a}$ Positive and negative numbers refer to the ring torsion angles ${ }^{3 \mathrm{a}}$ and italic numbers to the relative conformational strain energies $\left(\mathrm{kJ} \mathrm{mol}^{-1}\right)$ given by Snyder ${ }^{9}$ after readjustment of the first values calculated by Dale. ${ }^{4 a}$

predominant. ${ }^{4,5,8,9}$ This first conformer of lowest energy, designated [3434] $]^{\dagger}$ or gtggttg ${ }^{\prime} \mathrm{g}^{\prime} \mathrm{tg}^{\prime} \mathrm{g}^{\prime} \mathrm{ttg}^{*}$ according to Dale's $\mathrm{s}^{4}$ and Snyder's ${ }^{9}$ respective conventions, possesses the ideal strain-free 'rectangular' diamond lattice structure, ${ }^{3,4,10 a}$ with four 'corners' corresponding to gg or $\mathrm{g}^{\prime} \mathrm{g}^{\prime}$ sequences and two parallel long chains roughly at van der Waals distance linked at each end by $\mathrm{C}_{2}$ bridges in a perspective drawing (Fig. 1). ${ }^{3}$ Among the conformers detected at higher energy, the second and the eighth ones, named [3344] or gtggtggttg $\mathrm{g}^{\prime} \mathrm{ttg}$ and [3335] or gtggtggtggtttg, respectively, present a 'quadrangular' conformation. ${ }^{4 a, 9}$ The unsymmetrical arrangement $\mathrm{gg}^{\prime}$ or $\mathrm{g}^{\prime} \mathrm{g}$ of two gauche bonds of opposite sign, generally excluded in open chains by the 1,5 pentane interaction, ${ }^{4 a}$ but apparently very common in medium rings, ${ }^{8}$ is encountered in several conformers, from the fourth to the seventh, with an increase to $\approx 100^{\circ}$ of one of the two dihedral angles. ${ }^{8,9}$

Simple substituents on cyclotetradecane are assumed not to influence the conformation of the ring itself, except by their bulk. ${ }^{3 a}$ An alkyl group, particularly a gem-dimethyl group, would be preferentially located in a corner position of the

\footnotetext{
${ }^{4}$ In Dale's convention, ${ }^{4}$ the numbers in brackets indicate the number of $\mathrm{C}-\mathrm{C}$ bonds between corner carbon atoms starting with the shortest. ${ }^{4,9}$ Thus the [3434] conformer has two 'three-bond' sides and two 'fourbond' sides.

${ }^{\ddagger}$ In Snyder's designation, ${ }^{9}$ the letters g, g', t, corresponding to gauche and trans bonds, refer to dihedral angles varying significantly from $+60^{\circ}$, $-60^{\circ}, 180^{\circ}$. They include the following ranges: $\left[+45^{\circ} \leq \mathrm{g} \leq+105^{\circ}\right.$, $\left.-45^{\circ} \leq \mathrm{g}^{\prime} \leq-105^{\circ}, \pm 165^{\circ} \leq \mathrm{t} \leq \pm 180^{\circ}\right]$ for cyclotetradecane ${ }^{8,9}$ and $\left[+50^{\circ} \leq \mathrm{g} \leq+126^{\circ},-50^{\circ} \leq \mathrm{g} \leq-126^{\circ}, \pm 158^{\circ} \leq \mathrm{t} \leq \pm 180^{\circ}\right]$ for 1 -azacyclotetradecan-2- one (14-membered ring monolactam) (vide infra). ${ }^{24}$ In our study, we have adopted the following convention: $+20^{\circ} \leq \mathrm{g} \leq+116-120^{\circ},-20^{\circ} \leq \mathrm{g}^{\prime} \leq-116-120^{\circ}, \pm 116-120^{\circ} \leq \mathrm{t} \leq$ $\pm 180^{\circ}$.
}

rectangular cyclotetradecane and a symmetrical bi-gemdimethyl substitution would favour the diamond-lattice conformation. ${ }^{11,12}$ Replacement of a $-\mathrm{CH}_{2}-$ group by $-\mathrm{O}-$, $-\mathrm{NR}-,-\mathrm{C}=\mathrm{O},-\mathrm{C}=\mathrm{N}-\mathrm{OH}$, etc. is considered to cause minimal perturbations ${ }^{3 a}$ and gives the same [3434] conformational preference for: (i) 1-oxa-, ${ }^{13}$ 1,3,8,10-tetraoxa- ${ }^{14} 1,8$-diaza- ${ }^{10 b, 15}$ and 1,8-dihydroxy-1,8-diaza- ${ }^{10 b, 16}$ cyclotetradecanes, (ii) cyclotetradecanone, ${ }^{17,18}$ cyclotetradecane-1,8-dione, ${ }^{11,19}$ cyclotetradecane oxime ${ }^{20}$ and tridecanolactone. $^{21}$

Insertion, into the saturated ring chain, of an amide linkage which presents a partial double-bond character, induces some strain in the molecule. The torsion angles adjacent to the amide group are expected to be about 60 and $120^{\circ}$ for the extreme case. ${ }^{22,23}$ Between the two possible configurations of the NH-CO function, the trans one ( $\mathrm{H}$ anti to the carbonyl oxygen atom) is strongly favoured ${ }^{3 \mathrm{~b}}$ and is in fact the exclusive conformation for $n$-membered ring lactams in which $n \geq 11 .^{24}$ Studies of 1 -azacyclotetradecane-2-one by low temperature NMR point to the presence in solution of at least two main conformers, while molecular mechanics calculations describe four possible structures (Fig. 2). ${ }^{24}$ The two conformers A and B of lowest energy present a [3434] shape with a trans amide group located on a 'four-bond' side. In contrast, in the two structures $\mathbf{C}$ and $\mathbf{D}$, the amide function is accommodated in a 'three-bond' side and the conformation $\mathbf{D}$, deriving from $\mathbf{C}$ by a $\mathrm{NH}-\mathrm{CO}$ moiety rotation eliminating two corners, is considered less favourable. Similarly, X-ray studies of substituted 14-ring monolactams reveal conformations derivable from the above shapes, as described by reports on two naturallyoccurring substances. ${ }^{25,26}$
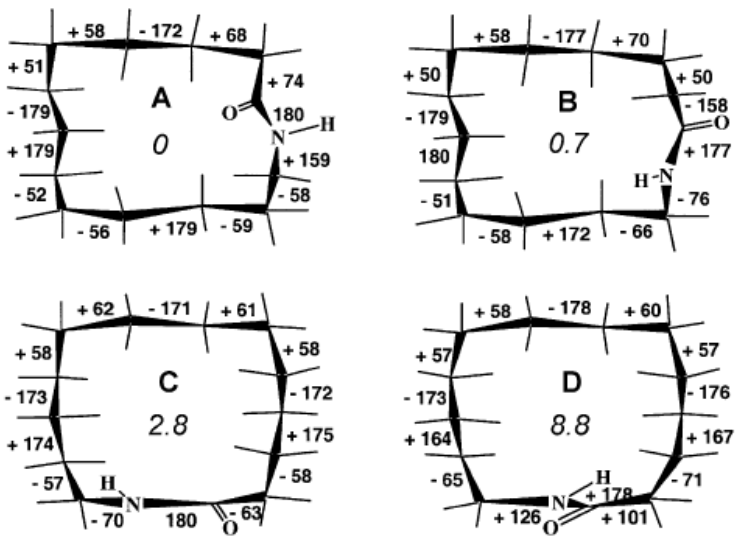

Figure 2. Top view representations of the 1-azacyclotetradecane-2-one conformers. ${ }^{24}$ Positive and negative numbers refer to the ring torsion angles and italic numbers to the relative conformational strain energies $\left(\mathrm{kJ} \mathrm{mol}^{-1}\right)$.

The X-ray diffraction of the symmetrical dilactam 1,8-diazacyclotetradecane-2,9-dione shows a centrosymmetric ring structure with the opposite $\mathrm{NH}-\mathrm{CO}$ links on the short 'sides' and adjacent angle values close to those observed in the monolactam conformer $\mathbf{D}^{27,28}$ The planes containing the amide groups are perpendicular to the average macrocyclic ring and the molecules are linked together in 
parallel sheets by intermolecular $\mathrm{N}-\mathrm{H} \cdots \mathrm{O}=\mathrm{C}$ hydrogen bonds.

Concerning the 14-membered ring compounds we are interesting on, they include, besides the two symmetrical lactam functions, two infrequently encountered hybrid ketal groups with endo- and exo-cyclic oxygens that would be expected to have a strong influence on the shape of the molecules (Scheme 1). Conformational investigations were conducted by: (i) NMR spectroscopy both in solution $\left({ }^{13} \mathrm{C}\right.$ and ${ }^{1} \mathrm{H}$ NMR, NOE difference) and in the solid state $\left({ }^{13} \mathrm{C}\right.$ SSNMR), (ii) molecular mechanics calculations (Monte Carlo simulations) using the AMBER force field, (iii) X-ray crystallography of one macrocycle. The data obtained in this last case were compared with those deduced from the SSNMR study of the same compound. This powerful technique, ${ }^{29}$ which offers the advantage of being easier to handle than XR diffraction, is particularly useful for studying molecular conformations that rapidly equilibrate in solution but are 'frozen out' in the crystalline state. The results obtained by the different approaches will be compared.

\section{Results and discussion}

Macrocyclic diketal dilactams 1-7 were prepared in two steps from $\beta$-aminoalcohols. ${ }^{1}$ The macrocyclization strategy was based on a $[1+1]$ cyclocondensation by transacetalization in acidic conditions of hydroxyamidoketals bearing a trans-amide group (Scheme 2). ${ }^{\text {lb }}$

Fourteen-membered macrocycles were generated under different diastereoisomeric forms depending on the chiral

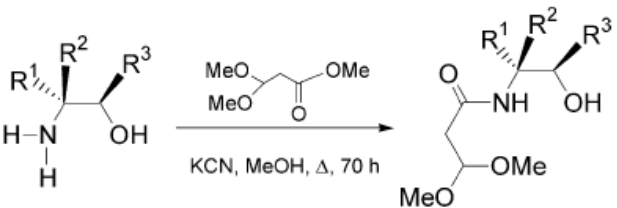

$$
\begin{aligned}
& \text { PTSA } \mid \underset{\text { or benzene. }}{\mathrm{CH}_{2} \mathrm{Cl}_{2}}
\end{aligned}
$$

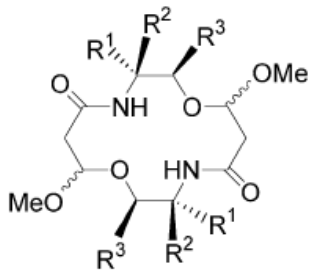

$$
\begin{aligned}
& R \text {-(-)-phenylglycinol } \quad: \mathrm{R}^{1}=\mathrm{Ph} ; \mathrm{R}^{2}=\mathrm{R}^{3}=\mathrm{H} \quad 1 \\
& S \text {-(+)-alaninol } \quad: R^{2}=M e ; R^{1}=R^{3}=H \quad 2 \\
& S \text {-(+)-leucinol } \quad: \mathrm{R}^{2}=\mathrm{iBu} ; \mathrm{R}^{1}=\mathrm{R}^{3}=\mathrm{H} \quad 3 \\
& S \text {-(-)-phenylalaninol } \quad: \mathrm{R}^{2}=\mathrm{Bn} ; \mathrm{R}^{1}=\mathrm{R}^{3}=\mathrm{H} \quad 4 \\
& \text { 1R,2S-(-)-norephedrine: } \mathrm{R}^{1}=\mathrm{H} ; \mathrm{R}^{2}=\mathrm{Me} ; \mathrm{R}^{3}=\mathrm{Ph} 5 \\
& \text { Aminoethanol } \quad: \mathrm{R}^{1}=\mathrm{R}^{2}=\mathrm{R}^{3}=\mathrm{H} \quad 6 \\
& \text { Dimethylaminoethanol: } \mathrm{R}^{1}=\mathrm{R}^{2}=\mathrm{Me} ; \mathrm{R}^{3}=\mathrm{H} \quad{ }^{\star} 7
\end{aligned}
$$

Scheme 2 .

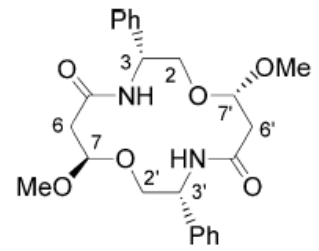<smiles>COC[C@H](NC(=O)C[C@@H](OC[C@@H](NC(=O)CC(OC)OC)c1ccccc1)c1ccccc1)c1ccccc1</smiles>

1b<smiles>[R]CC(=O)NC([R])CO[C@H](CC(=O)NC([R])CO[C@H](C)OC)OC</smiles>

1a: $\beta$-OMe 1c: $\alpha-\mathrm{OMe}$<smiles>[R7]C(CO[C@H](CC(=O)N[C@@H]([R])OC)OC)NC(=O)C[C@@H](OC)OCC([R])OC</smiles>
2b: $\quad \mathrm{R}^{2}=\mathrm{Me}$
2a: $\alpha-\mathrm{OMe}$
2c : $\beta$-OMe
3b : $\quad R^{2}=i B u$
3a: $\alpha$-OMe $3 \mathbf{c}: \beta-\mathrm{OMe}$
4b : $\quad R^{2}=B n$
4a : $\alpha-\mathrm{OMe}$
$4 c$ : $\beta$-OMe<smiles>COC(CC(=O)NC(C)C(O[C@H](CC(=O)NC(C)[C@H](C)c1ccccc1)c1ccccc1)c1ccccc1)OC</smiles>

$5 \mathbf{b}$<smiles>[R]C([R])(CO[C@@H](CC(=O)NC([R])([R])CO[C@H](C)OC)OC)NC(=O)C[C@@H](C)OC</smiles><smiles>[R]C([R])(COC)NC(=O)CC(OC)OCC([R])([R])OC</smiles>

$6 b$

$7 \mathrm{~b}$

$\mathrm{R}=\mathrm{H}$
$\mathrm{R}=\mathrm{Me}$

$6 c$

7c

Scheme 3.

or achiral character of the starting $\beta$-aminoalcohols (Scheme 3).

The chiral series provided three diastereoisomers: an unsymmetrical isomer $\mathbf{b}$, in which the two OMe substituents are in a trans configuration and two isomers a and $\mathbf{c}$ of $C_{2}$ symmetry, in which the two OMe groups are in a cis arrangement, $\mathbf{a}$ and $\mathbf{c}$ differing from each other, respectively, by the trans or cis relationship of the OMe and R groups. The achiral series led to two isomers $\mathbf{b}$ and $\mathbf{c}$ that both possessed some symmetry (center in $\mathbf{b}, C_{2}$ axis in $\mathbf{c}$ ).

\subsection{Liquid NMR studies}

Complete assignments of the liquid NMR spectra of all the macrocycles were previously reported. ${ }^{1}$ In ${ }^{13} \mathrm{C}$ and ${ }^{1} \mathrm{H}$ 
Table 1. Liquid ${ }^{13} \mathrm{C}$ NMR chemical shifts ( $\delta$ in ppm) of macrocycles 1-7

\begin{tabular}{|c|c|c|c|c|c|c|}
\hline \multirow[t]{2}{*}{ Compound } & \multicolumn{6}{|c|}{ Carbon } \\
\hline & $\overline{\mathrm{C}_{6}}$ & $\mathrm{C}_{3}$ & $\mathrm{OMe}$ & $\mathrm{C}_{2}$ & $\mathrm{C}_{7}$ & $\mathrm{CO}$ \\
\hline $1 a$ & 40.0 & 52.5 & 54.5 & 67.6 & 100.1 & 167.9 \\
\hline 1b chain 1 & 39.8 & 51.9 & 53.8 & 70.1 & 99.8 & 168.0 \\
\hline chain $1^{\prime}$ & 41.3 & 52.4 & 52.7 & 67.1 & 101.0 & 168.4 \\
\hline $1 \mathrm{c}$ & 41.2 & 52.5 & 53.2 & 70.5 & 101.2 & 168.4 \\
\hline $2 \mathrm{a}$ & 39.9 & 44.8 & 54.4 & 66.8 & 99.9 & 167.9 \\
\hline $\mathbf{2 b}$ chain 1 & 39.4 & 44.2 & $54.2^{\mathrm{a}}$ & 71.0 & 99.7 & 167.8 \\
\hline chain $1^{\prime}$ & 41.9 & 44.6 & $52.8^{\mathrm{a}}$ & 65.7 & 101.3 & 168.3 \\
\hline $2 \mathrm{c}$ & 41.5 & 44.7 & 52.7 & 70.4 & 100.9 & 168.3 \\
\hline $3 \mathbf{a}$ & 39.4 & 46.7 & 54.9 & 64.6 & 99.7 & 167.8 \\
\hline $3 \mathbf{b}$ chain 1 & 39.0 & 46.9 & $54.8^{\mathrm{a}}$ & 70.3 & 99.6 & 167.7 \\
\hline chain $1^{\prime}$ & 42.1 & 46.3 & $52.6^{\mathrm{a}}$ & 63.8 & 101.5 & 168.5 \\
\hline $3 \mathrm{c}$ & 41.6 & 47.0 & 52.8 & 69.6 & 101.2 & 168.4 \\
\hline $4 a$ & 40.3 & 50.1 & 54.4 & 65.4 & 100.3 & 168.0 \\
\hline $4 b$ chain 1 & 39.9 & 49.6 & $53.8^{\mathrm{a}}$ & 68.3 & 100.0 & 167.9 \\
\hline chain $1^{\prime}$ & 42.1 & 49.6 & $53.7^{\mathrm{a}}$ & 65.1 & 101.6 & 168.5 \\
\hline $4 c$ & 41.5 & 50.1 & 53.8 & 67.7 & 101.4 & 168.3 \\
\hline $5 a$ & 40.6 & 50.1 & 56.5 & 78.0 & 98.6 & 167.9 \\
\hline $5 \mathbf{b}$ chain 1 & 40.8 & 50.8 & 54.9 & 81.6 & 98.1 & 168.2 \\
\hline chain $1^{\prime}$ & 41.8 & 49.0 & 55.1 & 77.5 & 102.2 & 168.5 \\
\hline $5 c$ & 40.9 & 47.9 & 54.6 & 80.7 & 100.0 & 167.8 \\
\hline $6 b$ & 40.6 & 39.0 & 53.9 & 64.6 & 100.6 & 168.8 \\
\hline $6 \mathrm{c}$ & 41.1 & 39.2 & 53.4 & 66.1 & 100.9 & 169.1 \\
\hline $7 b$ & 42.2 & 53.6 & 53.0 & 73.3 & 100.8 & 168.6 \\
\hline $7 \mathrm{c}$ & 41.9 & 53.5 & 54.2 & 72.8 & 101.3 & 168.5 \\
\hline
\end{tabular}

${ }^{\text {a }}$ Values which may be inverted.

NMR, chiral isomers $\mathbf{a}$ and $\mathbf{c}$ and achiral compounds $\mathbf{b}$ and $\mathbf{c}$ showed one signal for each pair of identical groups of the macrocycle, while chiral isomers b exhibited double signals owing to the asymmetry of the two ring chains, which could be clearly distinguished using two-dimensional NMR and INEPT long-range experiments. ${ }^{1 \mathrm{~b}, 30}$ Comparison of these NMR data (chemical shifts, coupling constants, NOE difference) was used in a first approach to the conformation of the diketal dilactams studied.
2.1.1. ${ }^{13} \mathrm{C}$ NMR. Chemical shifts are collected in Table 1 . For each carbon, a small variation in shielding is observed depending on the nature of the substituents $\mathrm{R}^{1}, \mathrm{R}^{2}$ and $\mathrm{R}^{3}$ and on the stereochemistry of the OMe group. The 3-monosubstituted compounds 1-4 display the following features: (i) the ring carbons $\mathrm{C}_{6}, \mathrm{C}_{2}, \mathrm{C}_{7}$ and $\mathrm{CO}$ appear at higher field and the OMe groups at lower field in isomers a than in isomers $\mathbf{c}$, (ii) identical effects occur between chain 1 and chain $\mathbf{1}^{\prime}$ of isomers $\mathbf{b}$ except for carbons $\mathrm{C}_{2}$, which show

Table 2. Liquid NMR chemical shifts and patterns of protons $\mathrm{H}_{7}, \mathrm{H}_{6 \mathrm{~A}}, \mathrm{H}_{6 \mathrm{~B}}$ in compounds 1-7

\begin{tabular}{|c|c|c|c|c|c|}
\hline Compound & $\mathrm{H}_{7} \delta(\mathrm{ppm})$ & $\mathrm{H}_{6 \mathrm{~A}} \delta(\mathrm{ppm})$ & $\mathrm{H}_{6 \mathrm{~B}} \delta(\mathrm{ppm})$ & Pattern $^{a}$ & $\Delta \nu=v_{6 \mathrm{~A}}-v_{6 \mathrm{~B}}(\mathrm{~Hz})$ \\
\hline 1a & 4.77 & 2.80 & 2.58 & $3 \mathrm{dd}$ & 89.0 \\
\hline $1 \mathrm{c}$ & 4.78 & 2.64 & 2.62 & $\mathrm{ABX}$ & 5.0 \\
\hline $\mathbf{1 b}$ chain 1 & 4.77 & 2.86 & 2.56 & $3 \mathrm{dd}$ & 120.3 \\
\hline chain $1^{\prime}$ & 4.82 & 2.60 & 2.59 & $\mathrm{ABX}$ & 3.7 \\
\hline $2 a$ & 4.77 & 2.74 & 2.55 & $3 d d$ & 98.0 \\
\hline $2 \mathrm{c}$ & 4.69 & 2.58 & 2.54 & $\mathrm{ABX}$ & 17.4 \\
\hline $2 b$ chain 1 & 4.74 & 2.77 & 2.50 & $3 d d$ & 108.0 \\
\hline chain $1^{\prime}$ & 4.75 & 2.56 & 2.53 & $\mathrm{ABX}$ & 11.6 \\
\hline $3 \mathrm{a}$ & 4.78 & 2.75 & 2.54 & $3 \mathrm{dd}$ & 87.0 \\
\hline $3 \mathrm{c}$ & 4.65 & 2.55 & 2.53 & $\mathrm{ABX}$ & 10.9 \\
\hline $3 \mathbf{b}$ chain 1 & 4.74 & 2.79 & 2.50 & $3 d d$ & 114.0 \\
\hline chain $1^{\prime}$ & 4.73 & 2.55 & 2.51 & $\mathrm{ABX}$ & 14.3 \\
\hline $4 a$ & 4.64 & 2.70 & 2.47 & $3 \mathrm{dd}$ & 92.0 \\
\hline $4 \mathrm{c}$ & 4.63 & 2.55 & 2.55 & $\mathrm{ABX} \approx \mathrm{d}+\mathrm{t}$ & 0 \\
\hline $4 b$ chain 1 & 4.63 & 2.76 & 2.47 & 3dd & 115.0 \\
\hline chain $1^{\prime}$ & 4.65 & 2.52 & 2.45 & $\mathrm{ABX}$ & 28.3 \\
\hline $5 \mathrm{a}$ & 4.55 & 2.78 & 2.76 & $\mathrm{ABX}$ & 6.1 \\
\hline $5 \mathrm{c}$ & 4.95 & 2.77 & 2.65 & $\mathrm{ABX} \approx 3 \mathrm{dd}$ & 47.6 \\
\hline $5 \mathbf{b}$ chain 1 & 4.49 & 2.83 & 2.65 & $3 \mathrm{dd}$ & 72.6 \\
\hline chain $1^{\prime}$ & 4.89 & 2.77 & 2.65 & $\mathrm{ABX} \approx 3 \mathrm{dd}$ & 49.8 \\
\hline $6 b$ & 4.77 & 2.66 & 2.56 & $\mathrm{ABX} \approx 3 \mathrm{dd}$ & 43.1 \\
\hline $6 \mathrm{c}$ & 4.69 & 2.63 & 2.59 & $\mathrm{ABX}$ & 34.5 \\
\hline $7 b$ & 4.70 & 2.55 & 2.45 & $\mathrm{ABX}$ & 39.8 \\
\hline $7 \mathrm{c}$ & 4.70 & 2.60 & 2.49 & $\mathrm{ABX} \approx 3 \mathrm{dd}$ & 44.1 \\
\hline
\end{tabular}

${ }^{\text {a }} \mathrm{ABX}$ system for $\Delta \nu<5 \times J_{6 \mathrm{~A}-6 \mathrm{~B}}$ with $J_{6 \mathrm{~A}-6 \mathrm{~B}}=13.4-16.1 \mathrm{~Hz}$. 
Table 3. Coupling constants $\left(J\right.$ in $\mathrm{Hz}$ ) of compounds 1-7 in liquid ${ }^{1} \mathrm{H}$ NMR

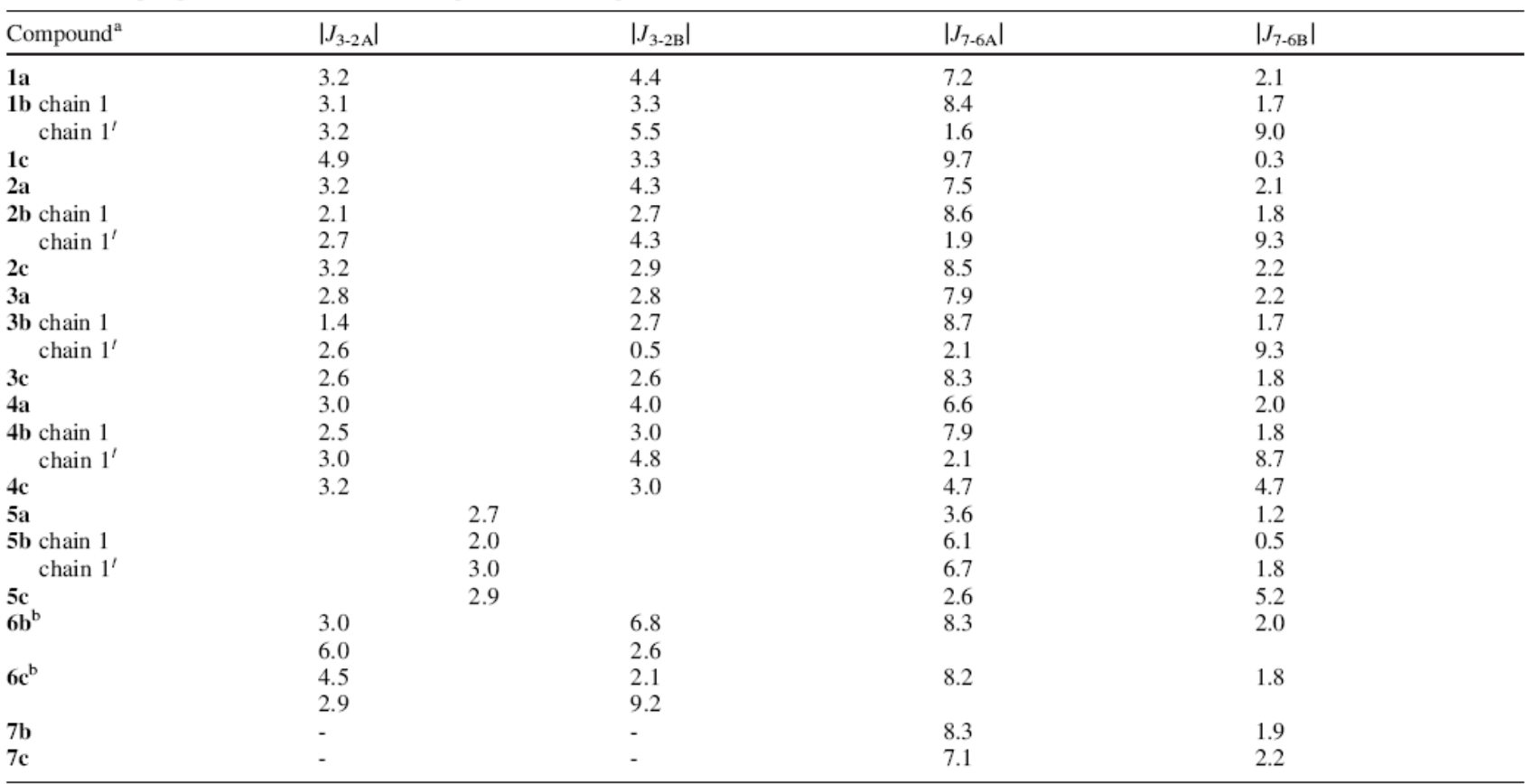

${ }^{a}$ For all compounds $\left|J_{2 \mathrm{~A}-2 \mathrm{~B}}\right|=8.8-10.0 \mathrm{~Hz} ; \Delta \nu=\nu_{2 \mathrm{~A}}-\nu_{2 \mathrm{~B}}=76-184 \mathrm{~Hz}$.

${ }^{\mathrm{b}}$ First line: $J_{3 \mathrm{~A}-2 \mathrm{X}}$; second line: $J_{3 \mathrm{~B}-2 \mathrm{X}}$.

an upfield shift in chain $1^{\prime}$, (iii) in isomers $\mathbf{b}$, chemical shift values of carbons $\mathrm{C}_{6}, \mathrm{C}_{7}, \mathrm{CO}$ and $\mathrm{OCH}_{3}$ (chain 1) are nearly identical to those of isomers a, while carbon $\delta$ values of chain $1^{\prime}$ are close to those of isomers $\mathbf{c}$.

These observations suggest that in each series, the variations in shielding depend essentially on the stereochemistry of the OMe group. Thus a trans relationship between OMe and the $\mathrm{R}^{1}$ or $\mathrm{R}^{2}$ substituents as it exists in isomers a and in chain 1 of isomers $b$ induces shielding of the nearest carbons $\mathrm{C}_{7}, \mathrm{C}_{6}$, $\mathrm{C}_{5}$ and $\mathrm{C}_{2}$, while a cis relationship as it exists in isomers $\mathbf{c}$ and in chain $1^{\prime}$ of isomers $\mathbf{b}$ causes deshielding of carbons $\mathrm{C}_{7^{\prime}}, \mathrm{C}_{6^{\prime}}, \mathrm{C}_{5^{\prime}}$ and $\mathrm{C}_{2}$.

2.1.2. ${ }^{1} \mathbf{H}$ NMR. Firstly, a careful analysis of the splitting of $\mathrm{H}_{6 \mathrm{~A}}$ and $\mathrm{H}_{6 \mathrm{~B}}$ due to coupling with the $\mathrm{H}_{7}$ proton (Table 2) reveals that in 3-monosubstituted compounds $\mathbf{1 - 4}$, these hydrogens appear as a doublet of doublet in each isomer a and as an ABX system in each isomer c. An identical splitting difference of protons $\mathrm{H}_{6 \mathrm{~A}}$ and $\mathrm{H}_{6 \mathrm{~B}}$ is also observed between the two chains of isomers $\mathbf{b}$. In fact, $\mathrm{H}_{6 \mathrm{~A}}$ hydrogens in $\mathbf{1} \mathbf{a}-\mathbf{4 a}$ and $\mathbf{1 b}-\mathbf{4 b}$ (chain 1) are curiously deshielded $(\Delta \delta \approx+0.16-+0.30 \mathrm{ppm})$ compared with all the other $\mathrm{H}_{6}$ protons. This effect may be due to a greater proximity of $\mathrm{H}_{6 \mathrm{~A}}$ and the OMe oxygen lone pair in these cases. This hypothesis is supported below. In the norephedrine series in which the macrocycles have two substituents $\left(\mathrm{R}^{2}=\mathrm{Me}\right.$ and $\mathrm{R}^{3}=\mathrm{Ph}$ ), the same observations can be made regarding the two chains of compound $\mathbf{5} \mathbf{b}$. In contrast, and surprisingly, an inversion occurs in the splitting of $\mathbf{5 a}$ and $\mathbf{5} \mathbf{c}$ that is a real $\mathrm{ABX}$ system for $\mathbf{5 a}$ and an $\mathrm{ABX}$ system close to $3 \mathrm{dd}$ $\left(\Delta \nu \approx 3 \times J_{6 \mathrm{~A}-6 \mathrm{~B}}\right)$ for $\mathbf{5 c}$. This last pattern is also present in achiral compounds $\mathbf{6 b}$ and $7 \mathbf{c}$.

Secondly, examination of coupling constants of $\mathrm{H}_{3}$ and $\mathrm{H}_{7}$ with their vicinal hydrogens provides information on their position in the ring (Table 3). Thus, in all the compounds, $\mathrm{H}_{3}$ hydrogens whose both coupling constants have small values $\left(J_{3-2 \mathrm{~A}}=1.4-4.9\right.$ and $\left.J_{3-2 \mathrm{~B}}=0.5-5.5 \mathrm{~Hz}\right)$ probably occupy an equatorial position bisecting the dihedral angle $\mathrm{H}_{2 \mathrm{~A}}-\mathrm{C}-\mathrm{H}_{2 \mathrm{~B}}$. Similarly, $\mathrm{H}_{7}$ protons, which in most compounds have widely different $J$ values $\left(J_{7-6 a x}=4.7-9.7\right.$, $J_{7-6 e q}=0.3-4.7 \mathrm{~Hz}$ ), very likely occupy an axial position with axial-axial and axial-equatorial coupling constants, respectively. One exception is, however, observed for $\mathbf{5 a}$ in which $\mathrm{H}_{7}$ protons show closer $J$ values $(3.6$ and $1.2 \mathrm{~Hz}$ ) corresponding to a pseudo-axial or equatorial position of $\mathrm{H}_{7}$ due to a modification of the ring shape.

Thirdly, a complementary study by the ${ }^{1} \mathrm{H}-{ }^{1} \mathrm{H}$ nuclear Overhauser effect (NOE) was made on compounds $\mathbf{1 c}, \mathbf{2 c}$, $\mathbf{6 c}$ and $7 \mathbf{c}$ to obtain further information on the spatial interactions. Irradiation of $\mathrm{H}_{7}$ produces nuclear Overhauser enhancements on: (i) $\mathrm{H}_{6 \mathrm{~B}}$ for which a differentiated effect with regard to $\mathrm{H}_{6 \mathrm{~A}}$ is clearly visible on compounds $\mathbf{6 c}$ and $7 \mathrm{c}$ but not on compounds $1 \mathrm{c}$ and $2 \mathrm{c}$, the $\Delta \nu$ values being

Table 4. (a) In normal characters: nuclear Overhauser effects (\%) observed on protons $\mathrm{H}_{x}$ by irradiation of $\mathrm{H}_{7}$ for compounds $1 \mathrm{c}, 2 \mathrm{c}, \mathbf{6 c}, 7 \mathrm{c}$; (b) in italic characters: interatomic distances $d_{\mathrm{H}_{y}-\mathrm{H}_{x}}$ (A) measured by molecular modeling

\begin{tabular}{llll}
\hline Compound & \multicolumn{3}{l}{ Proton } \\
\cline { 2 - 4 } & $\mathrm{H}_{2 \mathrm{~A}}$ & $\mathrm{H}_{2 \mathrm{~B}}$ & $\mathrm{H}_{6 \mathrm{~B}}$ \\
\hline $\mathbf{1 c}$ & $0.0 \%$ & $3.6 \%$ & $5.0 \%$ \\
& 2.93 & 2.41 & 2.52 \\
$\mathbf{2 c}$ & $1.0 \%$ & $3.7 \%$ & $4.2 \%$ \\
& 2.89 & 2.42 & 2.52 \\
$\mathbf{6 c}$ & $0.5 \%$ & $4.0 \%$ & $3.1 \%$ \\
& 2.92 & 2.38 & 2.53 \\
$\mathbf{c}$ & $0 \%$ & $3.9 \%$ & $5.2 \%$ \\
& 2.91 & 2.36 & 2.53 \\
\hline
\end{tabular}


large in the first case and small in the second case (Table 2), (ii) $\mathrm{H}_{2 \mathrm{~B}}$ whereas no appreciable effect is observed on $\mathrm{H}_{2 \mathrm{~A}}$ (Table 4). This last result points to a partial strain in the assumed high flexibility of the macrocycles which would produce an effect on both $\mathrm{H}_{2}$ protons. In contrast, the observed NOE indicates that $\mathrm{H}_{7}$ must be cis to $\mathrm{H}_{2 \mathrm{~B}}$ and trans to $\mathrm{H}_{2 \mathrm{~A}}$. Taking into account the axial position of $\mathrm{H}_{7}$ and the equatorial position of $\mathrm{H}_{3}$ in $1 \mathrm{c}$ and $2 \mathrm{c}$ (see above), these results identify $\mathrm{H}_{2 \mathrm{~A}}$ as $\mathrm{H}_{2 e q}$ and $\mathrm{H}_{2 \mathrm{~B}}$ as $\mathrm{H}_{2 \mathrm{ax}}$ in all isomers $\mathrm{c}$, in particular in the 3-disubstituted compound $7 \mathrm{c}$, for which $J_{3-2}$ coupling constants are not available.

\subsection{Molecular modeling}

The Monte-Carlo calculations indicate a certain flexibility of these macrocyclic ligands, for which ten conformations are generally observed within $4-13 \mathrm{~kJ} \mathrm{~mol}^{-1}$ of the global minimum (Supplementary material SM). However, in around $60 \%$ of cases (11/19), a greater energy difference is observed between the first two conformers than between the five following ones taken two by two $\left(\Delta E_{2-1}>\Delta E_{3-2}\right.$ or $\Delta E_{4-3}$ or $\left.\Delta E_{5-4}\right)$. Hence, because a detailed comparison of all the conformers would have been tedious and difficult, the modeling study was conducted, for most of the compounds, on the first conformer of lowest energy, and only exceptionally on the following ones.

The calculated $\mathrm{H}-\mathrm{H}$ dihedral angles (SM) for conformer 1 of most of the chiral compounds (1a-c, 2a-c, 3b,c, 4c, 5a,c) point to: (i) an equatorial position of $\mathrm{H}_{3}$ bisecting the angle $\mathrm{H}_{2 \mathrm{ax}}-\mathrm{C}-\mathrm{H}_{2 e q}\left(\theta_{\mathrm{H}_{3}, \mathrm{H}_{2 \mathrm{x}}}=33-63^{\circ}\right.$ and $\left.\theta_{\mathrm{H}_{3}, \mathrm{H}_{2 \mathrm{~m}}}=54-85^{\circ}\right)$ and corresponding to an axial position of the $3,3^{\prime}-\mathrm{R}$ groups ( $\alpha$-axial in 1, $\beta$-axial in $2-5$ ) and to an equatorial position of the $2,2^{\prime}-\mathrm{Ph}$ substituents in macrocycles $\mathbf{5 a}$ and $\mathbf{5} \mathbf{c}$, (ii) an axial position of $\mathrm{H}_{7}\left(\theta_{\mathrm{H}_{7}, \mathrm{H}_{6 \mathrm{x}}}=168-180^{\circ}\right)$ corresponding to an energetically favourable equatorial position of the $\alpha$ or $\beta$-OMe groups. These observations, not made in the first conformer of $3 \mathrm{a}$ and $4 \mathrm{a}$, are consistent, however, with the second conformer. These results agree with the above ${ }^{1} \mathrm{H}$ NMR data: equatorial and axial characters of $\mathrm{H}_{3}$ and $\mathrm{H}_{7}$, respectively. The preferential 3-R substituent axial position and the preferential OMe group equatorial situation may produce a partial strain in these otherwise flexible compounds, as suggested by the NOE results (vide supra). Two exceptions are, however, to be noted for the chain $1^{\prime}$ of macrocycles $\mathbf{4} \mathbf{b}$ and $\mathbf{5} b$, in which $\mathrm{H}_{3^{\prime}}$ or $\mathrm{H}_{7^{\prime}}$ or both protons occupy an opposite situation on the first conformers, while the above conformation $\left(\mathrm{H}_{3^{\prime} e q}\right.$ and $\mathrm{H}_{7^{\prime} \mathrm{ax}}$ ) occurs only on conformer 5 of $\mathbf{4 b}$ and on conformer 8 of $\mathbf{5 b}$. In the NMR spectrum of $\mathbf{4 b}$, the $J_{3^{\prime}-2^{\prime} \mathrm{B}}$ value $(4.8 \mathrm{~Hz})$, which corresponds to the maximum of the observed $J_{3-2}$ values, is consistent with an equilibrium between the conformers of lowest energy. Also, the assumed equatorial position of $\mathrm{H}_{7}$ in compound 5 a (see above) is confirmed for the chain $1^{\prime}$ of the second conformer $\left(\theta_{\mathrm{H}_{7^{\prime}}, \mathrm{H}_{6^{\prime} \mathrm{ax}}}=55^{\circ}\right.$ and $\left.\theta_{\mathrm{H}_{7^{\prime}}, \mathrm{H}_{6^{\prime} \text { qq }}}=62^{\circ}\right)$.

Measurements of the $\mathrm{H}_{6}-\mathrm{OMe}$ interatomic distances indicate a shorter $d_{\mathrm{H}_{\mathrm{ex}}}-\mathrm{OMe}$ for compounds a and $\mathbf{b}$ (chain 1) (2.69-2.76 $\AA$ ) than for compounds $\mathbf{c}$ and $\mathbf{b}$ (chain $1^{\prime}$ ) (2.80-2.87 $\AA$ ) (SM). These indications are evidenced in most of conformers 1 (1a-c, $2 \mathrm{a}-\mathrm{c}, 3 \mathrm{~b}-\mathrm{c}, \mathbf{4 c}, 5 \mathrm{a}, \mathrm{c})$, in conformer 2 of $3 a$ and $4 a$, in conformer 5 of $4 b$ and in conformer 8 of $\mathbf{5 b}$. They are consistent with the deshielding observed for $\mathrm{H}_{6 \mathrm{~A}}$ in compounds a and b (chain 1) (see above) that is to say in the chain in which the 7-OMe group is in a trans relationship with the 3-R substituent. C-C dihedral angles of the 19 macrocycles are given in Table 5. All exhibit invariable transoid conformations along the two bonds $\mathrm{C}_{3}-\mathrm{N}_{4}-\mathrm{CO}-\mathrm{C}_{6}$ corresponding to the amide links (torsions: $172-180^{\circ}$ ) and the two bonds $\mathrm{C}_{7^{\prime}}-\mathrm{O}_{1}-\mathrm{C}_{2}-\mathrm{C}_{3}$ (torsions: $121-180^{\circ}$ ), and gauche conformations along the bonds $\mathrm{O}_{1}-\mathrm{C}_{2}-\mathrm{C}_{3}-\mathrm{N}_{4}$ (torsions: $34-72^{\circ}$ ) and $\mathrm{C}_{5}-\mathrm{C}_{6}-\mathrm{C}_{7}-\mathrm{O}_{1^{\prime}}$ (torsions: $50-75^{\circ}$ ). In contrast, the values of the $\mathrm{C}_{2}-\mathrm{C}_{3}-\mathrm{N}_{4}-$ $\mathrm{C}_{5}, \mathrm{~N}_{4}-\mathrm{C}_{5}-\mathrm{C}_{6}-\mathrm{C}_{7}$ and $\mathrm{C}_{6}-\mathrm{C}_{7}-\mathrm{O}_{1^{\prime}}-\mathrm{C}_{2^{\prime}}$ angles range from 22 to $180^{\circ}$ and correspond to gauche or trans (anti) conformations depending on the macrocycle stereochemistry and the nature of the substituents.

In the achiral compounds, structures of the [3434]-type are observed for the symmetry center macrocycles $\mathbf{6 b}$ and $7 \mathbf{b}$ (structure $\mathrm{Ib}$ ) in which the trans-OMe groups are accommodated in the two opposite corners $\mathrm{C}_{7}, \mathrm{C}_{7^{\prime}}$, while the $\mathrm{C}_{3}$, $\mathrm{C}_{3^{\prime}}$ carbons form the other two corners (Fig. 3). The $\mathrm{O}_{1}, \mathrm{O}_{1^{\prime}}$ atoms, located on the 'three-bond' sides, point inwards into the ring. The trans-amide functions, situated on the 'fourbond' sides, are set perpendicular to the macrocyclic plane and display the conformationally more stable opposite orientation. ${ }^{27}$ The rectangular diamond-lattice structure is magnified in compound $7 \mathbf{b}\left(\mathrm{N}_{4}-\mathrm{C}_{5}-\mathrm{C}_{6}-\mathrm{C}_{7}, \mathrm{~N}_{4^{\prime}}-\mathrm{C}_{5^{\prime}}-\mathrm{C}_{6^{\prime}}-\right.$ $\mathrm{C}_{7^{\prime}}$ dihedral angles $= \pm 145^{\circ}$ in $6 \mathbf{b}, \pm 172^{\circ}$ in $\left.7 \mathbf{b}\right)$ by the presence in $\mathrm{C}_{3}, \mathrm{C}_{3^{\prime}}$ of gem-dimethyl groups (see above). ${ }^{11,12}$ In the cis-OMe isomers $6 \mathrm{c}$ and $7 \mathrm{c}$ (structure IIc), the potential rectangular shape is distorted compared with $\mathbf{6 b}$ and $7 \mathbf{b}$ by $\mathrm{a} \approx 180^{\circ}$ rotation of one $\mathrm{NH}-\mathrm{CO}$ group, eliminating the $\mathrm{C}_{7}, \mathrm{C}_{7^{\prime}}$ corners and causing the appearance in $\mathrm{C}_{6}$ and $\mathrm{C}_{6^{\prime}}$ of $\mathrm{g}^{\prime} \mathrm{g}$ sequences accompanied by an increase to 95 or $119^{\circ}$ of one of the corresponding dihedral angles as indicated above for some conformers of cyclotetradecane. ${ }^{8}$ The NH-CO links are still perpendicular to the macrocycle, but in this case they are located on the pseudo three-bond sides and oriented in the same direction, in agreement with a $C_{2}$ symmetry, while the $\mathrm{O}_{1}$ and $\mathrm{O}_{1^{\prime}}$ atoms, still pointing into the ring, now occupy the middle position of the four-bond side (Fig. 3).

In the chiral compounds $\mathbf{1 - 5}$, the conformation of the molecules is modified, compared with the above shapes, by a $90^{\circ}$ rotation of one or both $\mathrm{NH}-\mathrm{CO}$ links, which take a position parallel to the average macrocycle plane, with the $\mathrm{C}=\mathrm{O}$ and $\mathrm{N}-\mathrm{H}$ bonds directed outwards from and inwards into the ring respectively. This arrangement allows the formation of intramolecular hydrogen bonds between the $\mathrm{NH}$ hydrogens and the endocyclic ketal oxygens of the other chain, which are invariably oriented inwards into the ring (Fig. 3). Thus while most of trans compounds b (2b-5b), exhibit only one $\mathrm{N}_{4}-\mathrm{H} \cdots \mathrm{O}_{1}$, bond, cis macrocycles a and $\mathrm{c}$ are characterized in most cases $[\mathbf{1 a}-\mathbf{3 a}, \mathbf{1 c}-\mathbf{3 c}, \mathbf{4} \mathbf{a}$ (conformer 2), $\mathbf{4 c}$ (conformer 5 ), $5 \mathrm{a}, \mathbf{5} \mathrm{c}]$ by the presence of two hydrogen bonds $\mathrm{N}_{4}-\mathrm{H}^{\cdots} \mathrm{O}_{1^{\prime}}$ and $\mathrm{N}_{4^{\prime}}-\mathrm{H}^{\cdots} \cdots \mathrm{O}_{1}$ consistent with a $C_{2}$ symmetry (SM).

All these molecules show $\mathrm{gg}^{\prime}$ or $\mathrm{g}^{\prime} \mathrm{g}$ arrangements for $\mathrm{C}_{6}$, $\mathrm{C}_{6^{\prime}}$ with $\mathrm{N}_{4}-\mathrm{C}_{5}-\mathrm{C}_{6}-\mathrm{C}_{7}$ and $\mathrm{C}_{5}-\mathrm{C}_{6}-\mathrm{C}_{7}-\mathrm{O}_{1^{\prime}}$ angles ranging from \pm 22 to $\pm 122^{\circ}$ (Table 5). They differ essentially in the values of the dihedral angles $\mathrm{C}_{2}-\mathrm{C}_{3}-\mathrm{N}_{4}-\mathrm{C}_{5}$ and 
Table 5. C-C torsional angles $\phi\left(^{\circ}\right)$ for macrocycles 1-7 $\left(+20^{\circ}<\mathrm{g}<+116-126^{\circ} ;-20^{\circ}<\mathrm{g}^{\prime}<-116-126^{\circ} ; \pm 116-126^{\circ}<\mathrm{t}< \pm 180^{\circ}\right.$

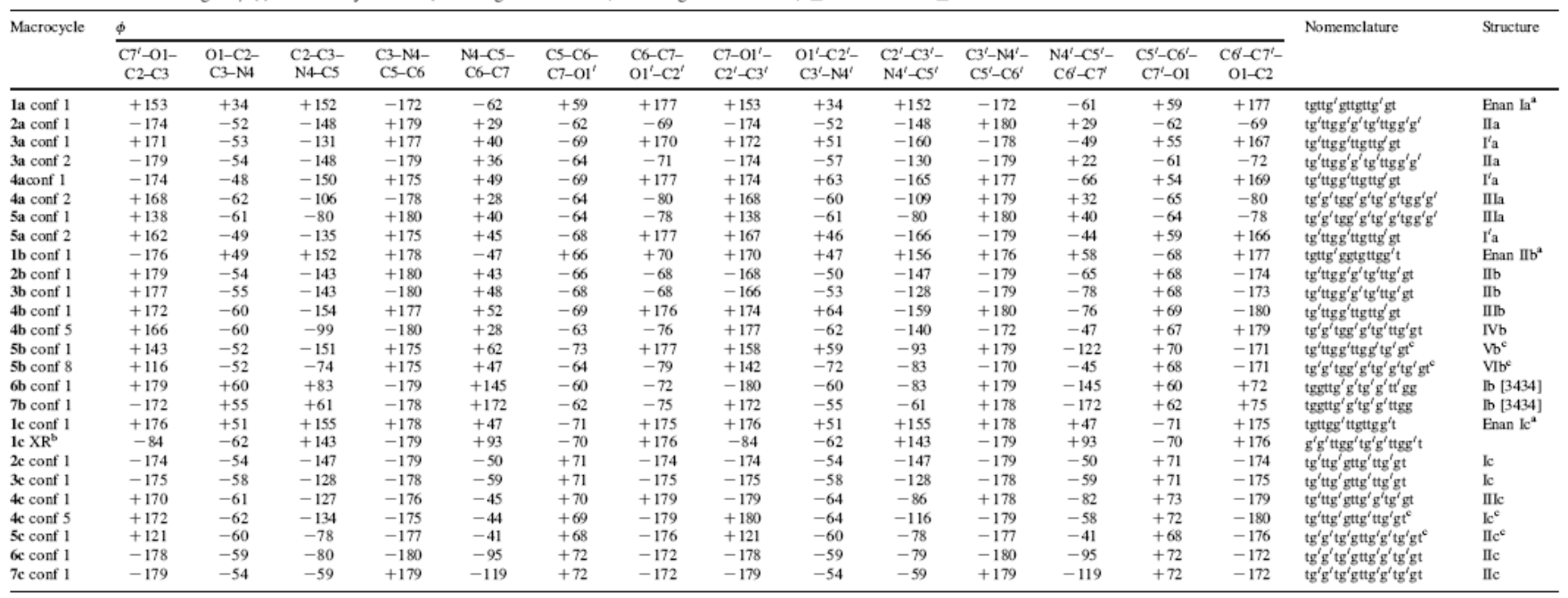

${ }^{2}$ Enan $=$ Enantiomer of structure

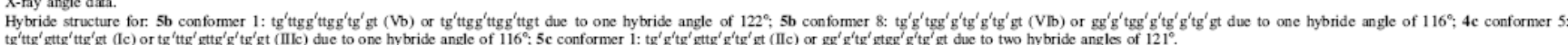



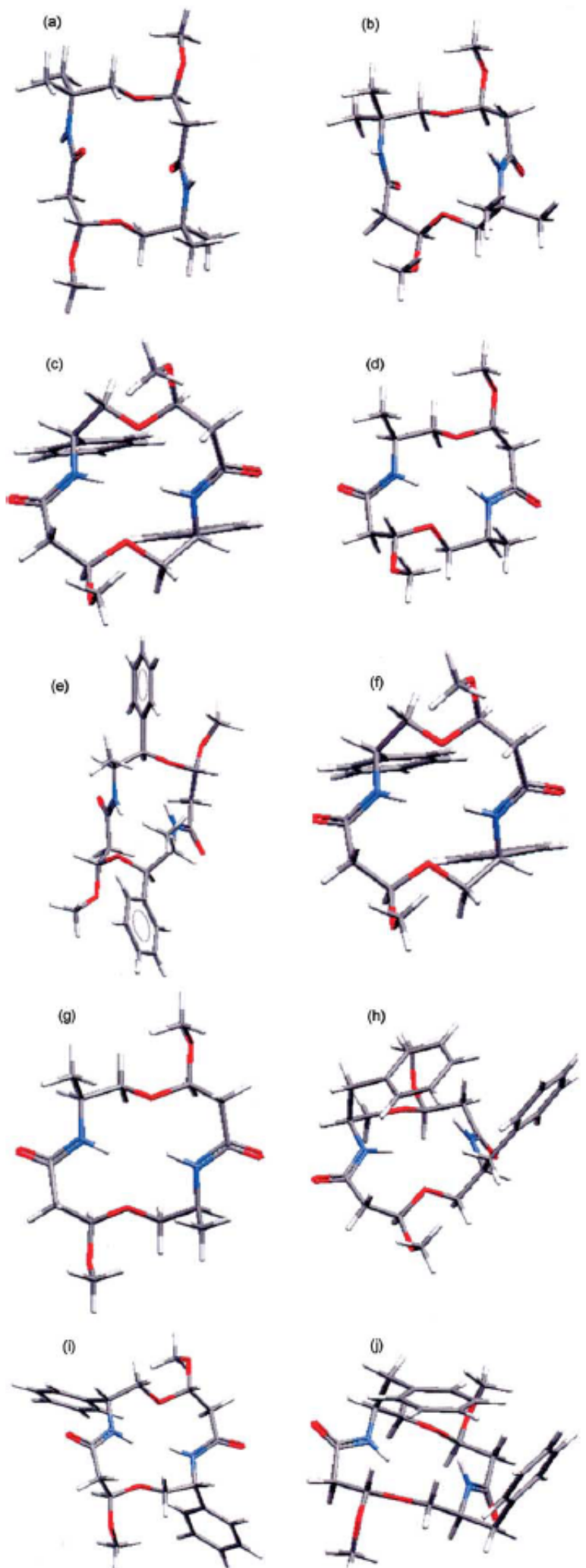

Figure 3. Top view representations of some diketal dilactam macrocycles (conformer 1) by molecular modeling: (a) $7 \mathrm{~b}$ : structure $\mathrm{Ib}$, (b) $7 \mathrm{c}$ : structure IIc, (c) 1a: enantiomer of structure Ia, (d) $2 \mathrm{a}$ : structure IIa, (e) $5 \mathrm{a}$ : structure IIIa, (f) 1c: enantiomer of structure Ic, (g) $2 \mathrm{c}$ : structure Ic, (h) $4 \mathrm{c}$ : structure IIIc, (i) 1b: enantiomer of structure IIb, (j) $4 \mathrm{~b}$ : structure IIIb.
$\mathrm{C}_{6}-\mathrm{C}_{7}-\mathrm{O}_{1^{\prime}}-\mathrm{C}_{2^{\prime}}$ which can correspond to either a trans or a gauche conformation.

Thus chiral macrocycles a present four different structures: (i) structure Ia: $\operatorname{tg}^{\prime} \operatorname{tgg}^{\prime} \operatorname{ttg}^{\prime} \operatorname{ttgg}^{\prime} \mathrm{t}$ (enantiomer of $\left.1 \mathrm{a}\right)^{8}$ and structure I'a: $\operatorname{tg}^{\prime} \mathrm{ttgg}^{\prime} \mathrm{ttgttg}^{\prime} \mathrm{gt}$ (3a conformer 1,4 a conformer 1 , 5a conformer 2) neither of which have a corner, and which present an identical chain 1 , but which differ in the sign of the chain $1^{\prime}$ gauche angles, causing a loss of symmetry in $I^{\prime} \mathrm{a}$, (ii) structure Ila: $\operatorname{tg}^{\prime} \operatorname{ttgg}^{\prime} \mathrm{g}^{\prime} \operatorname{tg}^{\prime} \mathrm{ttgg}^{\prime} \mathrm{g}^{\prime}$ (2a conformer 1, 3a conformer 2) characterized by the presence of corners at $\mathrm{C}_{7}, \mathrm{C}_{7^{\prime}}$, (iii) structure IIIa: $\operatorname{tg}^{\prime} \mathrm{g}^{\prime} \operatorname{tgg}^{\prime} \mathrm{g}^{\prime} \operatorname{tg}^{\prime} \mathrm{g}^{\prime} \operatorname{tgg}^{\prime} \mathrm{g}^{\prime}$ (4a conformer 2, 5a conformer 1) which has corners at $\mathrm{C}_{3}, \mathrm{C}_{3^{\prime}}$ and $\mathrm{C}_{7}, \mathrm{C}_{7^{\prime}}$.

Chiral compounds $\mathbf{c}$ present three different structures: (i) structure Ic: $\operatorname{tg}^{\prime} \mathrm{ttg}^{\prime} \mathrm{gttg}^{\prime} \mathrm{ttg}^{\prime} \mathrm{gt}$, the most frequently observed (enantiomer of $\mathbf{1 c},{ }^{8} \mathbf{2 c}, \mathbf{3 c}, \mathbf{4}$ c conformer 5 ), which has no corner; (ii) structure IIc: $\operatorname{tg}^{\prime} \mathrm{g}^{\prime} \operatorname{tg}^{\prime} \mathrm{gttg}^{\prime} \mathrm{g}^{\prime} \mathrm{tg}^{\prime} \mathrm{gt}$ (5c conformer 1) characterized by the presence of two corners at $\mathrm{C}_{3}, \mathrm{C}_{3^{\prime}}$ as previously observed in achiral macrocycles $6 \mathrm{c}$ and $7 \mathrm{c}$; the three compounds differ essentially in some lower dihedral angle values in $\mathbf{5}$ : $\mathrm{N}_{4}-\mathrm{C}_{5}-\mathrm{C}_{6}-\mathrm{C}_{7}^{\prime}, \mathrm{N}_{4^{\prime}}-\mathrm{C}_{5^{\prime}}-\mathrm{C}_{6^{\prime}}-\mathrm{C}_{7^{\prime}}\left(95\right.$ and $119^{\circ}$ in $6 \mathrm{c}$ and $7 \mathrm{c}$,

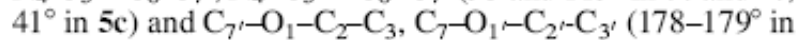
$6 \mathrm{c}$ and $7 \mathrm{c}, 121^{\circ}$ in $5 \mathrm{c}$ (limit value between trans and gauche conformations)]; (iii) structure IIIc: $\operatorname{tg}^{\prime} \mathrm{ttg}^{\prime} \mathrm{gttg}^{\prime} \mathrm{g}^{\prime} \mathrm{tg}^{\prime} \mathrm{gt}$ ( $\mathbf{4 c}$ conformers 1-4), which has a single corner at $C_{3^{\prime}}$ with no symmetry, and which is composed of chain 1 of Ic and chain $1^{\prime}$ of IIc. Structures Ic, IIc and IIIc differ in the values of the four angles $\mathrm{C}_{2}-\mathrm{C}_{3}-\mathrm{N}_{4}-\mathrm{C}_{5}, \mathrm{C}_{2^{\prime}}-\mathrm{C}_{3^{\prime}}-\mathrm{N}_{4}-\mathrm{C}_{5^{\prime}}$ and $\mathrm{C}_{6}-\mathrm{C}_{7}-\mathrm{O}_{1}-\mathrm{C}_{2^{\prime}}, \mathrm{C}_{6^{\prime}}-\mathrm{C}_{7^{\prime}}-\mathrm{O}_{1}-\mathrm{C}_{2}$, as seen above.

Chiral macrocycles b, whose chain 1 possesses the stereochemistry of compounds a and chain $1^{\prime}$ the stereochemistry of compounds $\mathbf{c}$, can adopt various combinations between structures Ia-IIIa and Ic-IIIc to give five different conformations IIb-VIb.

The representation of compounds with identical stereochemistry, for example macrocycles c, along a horizontal $\mathrm{C}_{7}-\mathrm{C}_{7}$ axis, with the OMe groups at each extremity, allows an interesting comparison of the global shape of the skeletons in function of the nature of the substituent (Fig. 4). Thus, all molecules of structure Ic [enantiomer of 1c, 2c, 3c (conformers 1) and $4 \mathrm{c}$ (conformer 5)] adopt a nearly identical pseudo-planar shape, while molecules with structure IIc show a convex form, slight in $6 \mathrm{c}$ and $7 \mathrm{c}$, and marked in $\mathbf{5 c}$.

\subsection{X-ray crystallography}

The previously determined crystal structure ${ }^{1 \mathrm{a}}$ of macrocycle 1c presents $\mathrm{Ph}$ and $\mathrm{OMe}$ substituents in an equatorial position. It shows a $\mathrm{g}^{\prime} \mathrm{g}^{\prime} \mathrm{ttgg}^{\prime} \mathrm{tg}^{\prime} \mathrm{g}^{\prime} \mathrm{ttgg} \mathrm{g}^{\prime} \mathrm{t}$ conformation close to that observed for $6 \mathrm{c}$ and $7 \mathrm{c}$ in molecular modeling (see

\footnotetext{
${ }^{5}$ Macrocycle 1a with an $R$ stereochemistry at $\mathrm{C}-3$ and C- 3 ' corresponds to a tgttg'gttgttg'gt structure. To establish comparison with the $3-S$ compounds $2 \mathrm{a}, 3 \mathrm{a}, 4 \mathrm{a}$ and $5 \mathrm{a}$, we have to consider the $3-S$ enantiomer of $1 \mathrm{a}$, the designation of which would be $\operatorname{tg}^{\prime} \mathrm{ttgg}^{\prime} \mathrm{ttg}^{\prime} \mathrm{ttgg}^{\prime} \mathrm{t}$. Identical modifications have to be made for 1 b (tgttg'ggtgttg $g^{\prime} \mathrm{t}$ ) and 1c (tgttgg' $\operatorname{tg} \operatorname{ttg} g^{\prime} \mathrm{t}$ ), enantiomers of which would have $\operatorname{tg}^{\prime} \operatorname{tgg}^{\prime} \mathrm{g}^{\prime} \operatorname{tg}^{\prime} \operatorname{tgg}^{\prime} \mathrm{gt}$ and $\operatorname{tg}^{\prime} \mathrm{ttg}^{\prime}$ gttg'ttg' $\mathrm{ttg}^{\prime}$ structures, respectively.
} 
(a)

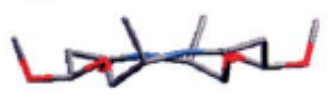

(c)

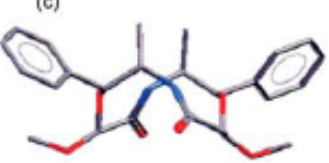

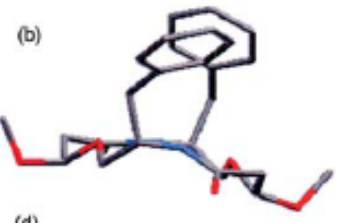

(d)

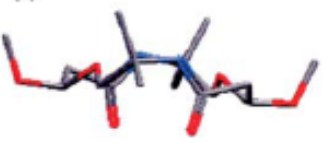

Figure 4. Representation by molecular modeling of some macrocycles $\mathrm{c}$ with a horizontal $\mathrm{C}_{7}-\mathrm{C}_{7^{r}}$ axis: (a) $2 \mathrm{c}$ conformer 1: structure Ic, (b) $4 \mathrm{c}$ conformer 5: structure Ic, (c) $5 \mathrm{c}$ conformer 1: structure IIc, (d) $7 \mathrm{c}$ conformer 1: structure IIc.

above) and characterized by a $C_{2}$ symmetry, gg $^{\prime}$ sequences at $\mathrm{C}_{6}, \mathrm{C}_{6^{\prime}}$ and corners at $\mathrm{C}_{2}, \mathrm{C}_{2^{\prime}}$ instead of $\mathrm{C}_{3}, \mathrm{C}_{3^{\prime}}$, consequent to a shift of the pseudo three- and four-bond sides (Table 5). Besides, in comparison with 1c (conformer 1), transoid conformations are also observed along the bonds $\mathrm{C}_{2}-\mathrm{C}_{3}-\mathrm{N}_{4}-\mathrm{C}_{5}, \mathrm{C}_{6}-\mathrm{C}_{7}-\mathrm{O}_{1^{\prime}}-\mathrm{C}_{2^{\prime}}$ and of course along the amide links, but in the crystal, the two $\mathrm{C}_{7^{\prime}}-\mathrm{O}_{1}-\mathrm{C}_{2}-\mathrm{C}_{3}$
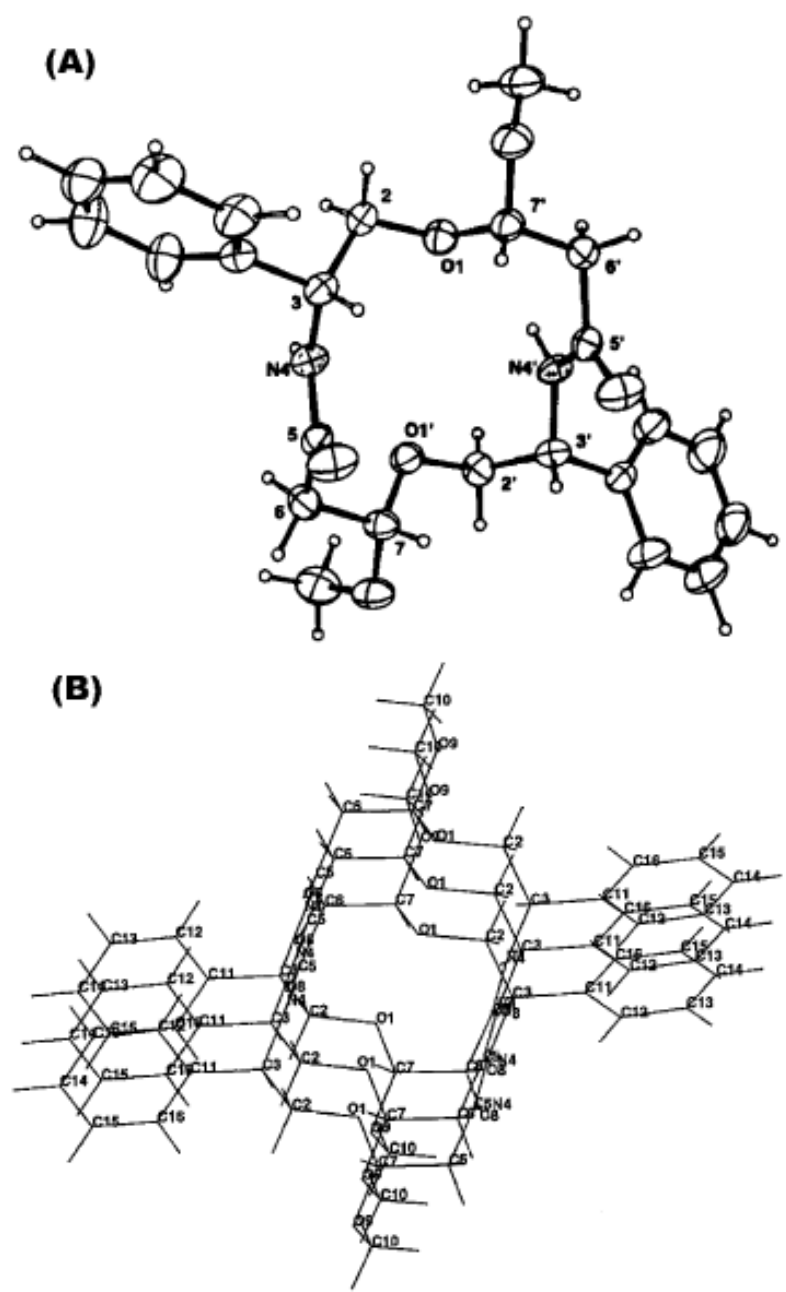

Figure 5. Phenyl macrocycle 1c: (A) X-ray structure; ${ }^{12}$ (B) Stacking of the molecules in parallel layers. ${ }^{12}$ bonds correspond to a gauche conformation. Also, the $\mathrm{O}_{1}$, $\mathrm{O}_{1^{\prime}}$ atoms still point into the ring but the $\mathrm{NH}-\mathrm{CO}$ links, located on the pseudo four-bond sides are now perpendicular to the macrocyclic plane and oriented in the same direction (Fig. 5). This arrangement in the crystal allows, the formation of $\mathrm{N}-\mathrm{H} \cdots \mathrm{O}=\mathrm{C}$ intermolecular hydrogen bonds $(2.95 \AA)$ that link the molecules together into sheets parallel to the binary axis, ${ }^{1 \mathrm{a}}$ while $\pi-\pi$ stacking interactions between the phenyl groups may also reinforce the cohesion of the structure.

\subsection{Solid state NMR analysis}

When no suitable crystals are available for an X-ray study, structural information concerning the solid state can be obtained by SSNMR. This technique, which unlike liquid NMR does not reflect an averaged conformation, permits the analysis of conformational constraints and polymorphic forms. Associated with magic angle spinning, the most common NMR experiment designed for this purpose is certainly the cross-polarization pulse scheme (CP-MAS), which allows a marked sensitivity enhancement and reduced acquisition time. Thus SSNMR spectra were first recorded for compounds $\mathbf{1 a}, \mathbf{1 b}$ and $\mathbf{1} \mathbf{c}$ to evaluate the effect of the relative positions of the $3,3^{\prime}$ - R substituents ( $\mathrm{Ph}$ in the present case) and the $7,7^{\prime}-\mathrm{OMe}$ groups on the ring conformation. Compounds $\mathbf{2 c}, \mathbf{3 c}, \mathbf{4 c}, \mathbf{6 b}$ and $\mathbf{6 c}$ were then analyzed to study the effect of the nature of the $3,3^{\prime}-\mathrm{R}$ substituent. Unfortunately, no suitable solid for NMR analysis was obtained for macrocycles $\mathbf{5}$.

The solid state NMR spectra of the three phenyl isomers 1a-c were recorded in the same conditions and compared with the corresponding liquid state ${ }^{13} \mathrm{C}$ NMR spectra, and for $1 \mathrm{c}$ to its X-ray diffraction data. ${ }^{1 \mathrm{a}} \mathrm{In}$ agreement with the liquid state ${ }^{13} \mathrm{C}$ NMR spectra, isomers a and $\mathrm{c}$ show one signal for each pair of identical groups of the macrocycle, while isomer b exhibits double signals (Table 6).

Concerning isomer $\mathbf{1 c}$, the presence of a high symmetry is readily apparent in its ${ }^{13} \mathrm{C}$ CP-MAS spectrum which shows 10 signals for the twenty carbons (SM). Several very interesting singularities can be noted in comparison with the ${ }^{13} \mathrm{C}$ liquid spectrum: (i) deshielding $(\Delta \delta+1.5 \mathrm{ppm})$ of the $\mathrm{CO}$ peak, which confirms the presence of intermolecular $\mathrm{C}=\mathrm{O} \cdots \mathrm{HN}$ hydrogen bonds ${ }^{31,32}$ as observed by X-ray diffraction analysis; (ii) shielding of the methoxy groups $(\Delta \delta-6.4 \mathrm{ppm})$, which can be distinguished from $\mathrm{C}_{3}$ carbons by dipolar dephasing experiments ${ }^{\uparrow, 33}$ and by comparison of the signal shape (sharp singlet for OMe and broadened singlet for $\mathrm{C}_{3}$ due to a quadrupolar coupling with the a ${ }^{14} \mathrm{~N}$ atom $) ;{ }^{34}$ (iii) shielding of $\mathrm{C}_{7}(\Delta \delta-6.2 \mathrm{ppm})$ and $C_{3}(\Delta \delta-1.2 \mathrm{ppm})$ carbon signals due to a $\gamma$-gauche effect known to give substantially shielded ${ }^{13} \mathrm{C}$ resonances $^{35-37}$ and resulting from $\mathrm{C}_{7^{\prime}}-\mathrm{O}_{1}-\mathrm{C}_{2}-\mathrm{C}_{3}$ gauche conformations, present in the solid state (torsions: $84^{\circ}$ from X-ray data) and not in the liquid state (torsions: $176^{\circ}$ from molecular modeling data). Complementary NMR experiments were conducted on this isomer by varying the

\footnotetext{
T Dipolar dephasing induces fast dephasing of protonated carbon signals $\left(\mathrm{CH}, \mathrm{CH}_{2}\right)$ except for those of $\mathrm{CH}_{3}$ groups which have a higher 'mobility'.
} 
Table 6. SSNMR ${ }^{13} \mathrm{C}$ chemical shifts ( $\delta$ in ppm) of compounds 1a-c, $2 \mathrm{c}-4 \mathrm{c}$ and $6 \mathrm{~b}, \mathrm{c}$. Values in italic correspond to chemical shift differences between solid and liquid states $\left(\Delta \delta=\delta_{\text {sol. }}-\delta_{\text {liq }}\right)$

\begin{tabular}{|c|c|c|c|c|c|c|}
\hline \multirow[t]{2}{*}{ Compound } & \multicolumn{6}{|l|}{ Carbon } \\
\hline & $\overline{\mathrm{C}_{6}}$ & $\overline{\mathrm{C}_{3}}$ & $\mathrm{O}-\mathrm{CH}_{3}$ & $\overline{\mathrm{C}_{2}}$ & $\overline{\mathrm{C}_{7}}$ & $\mathrm{C}=\mathrm{O}$ \\
\hline 1a & $\begin{array}{l}43.2 \\
+3.2\end{array}$ & $\begin{array}{l}54.0^{2} \\
+1.5\end{array}$ & $\begin{array}{l}54.0^{2} \\
-0.5\end{array}$ & $\begin{array}{l}74.7 \\
+7.1\end{array}$ & $\begin{array}{l}102.6 \\
+2.5\end{array}$ & $\begin{array}{l}169.4 \\
+1.5\end{array}$ \\
\hline 1b chain 1 & $\begin{array}{l}43.2^{2} \\
+3.4\end{array}$ & $\begin{array}{l}54.0^{2} \\
+2.1\end{array}$ & $\begin{array}{l}54.0^{2} \\
+0.2\end{array}$ & $\begin{array}{l}74.7 \\
+46\end{array}$ & $\begin{array}{r}103.5 \\
+3.7\end{array}$ & $\begin{array}{l}169.4^{2} \\
+1.4\end{array}$ \\
\hline chain $1^{\prime}$ & $\begin{array}{r}43.2^{2} \\
+1.9\end{array}$ & $\begin{array}{l}51.1 \\
-1.3\end{array}$ & $\begin{array}{l}46.8 \\
-5.9\end{array}$ & $\begin{array}{l}67.1 \\
0.0\end{array}$ & $\begin{array}{l}94.6 \\
-6.4\end{array}$ & $\begin{array}{l}169.4^{2} \\
-1.0\end{array}$ \\
\hline 1c & $\begin{array}{l}42.9 \\
+1.7\end{array}$ & $\begin{array}{l}51.3 \\
-1.2\end{array}$ & $\begin{array}{l}46.8 \\
-6.4\end{array}$ & $\begin{array}{l}67.3 \\
-3.2\end{array}$ & $\begin{array}{l}94.9 \\
-6.3\end{array}$ & $\begin{array}{l}169.9 \\
+1.5\end{array}$ \\
\hline $2 \mathrm{c}$ & $\begin{array}{l}40.1 \\
-1.4\end{array}$ & $\begin{array}{l}46.1 / 45.4^{\mathrm{b}} \\
+1.4 /+0.7\end{array}$ & $\begin{array}{l}48.7 \\
-4.0\end{array}$ & $\begin{array}{l}71.1 \\
+0.7\end{array}$ & $\begin{array}{l}100.9 \\
0.0\end{array}$ & $\begin{array}{l}171.0 / 170.2^{\mathrm{b}} \\
+2.7 /+1.9\end{array}$ \\
\hline $3 \mathrm{c}$ polymorph $1^{\mathrm{C}}$ & $\begin{array}{l}42.0 \\
+0.4\end{array}$ & $\begin{array}{l}47.9 \\
+0.9\end{array}$ & $\begin{array}{l}54.5 \\
+1.7\end{array}$ & $\begin{array}{l}72.3 \\
+2.7\end{array}$ & $\begin{array}{l}103.5 \\
+2.3\end{array}$ & $\begin{array}{l}169.0 \\
+0.6\end{array}$ \\
\hline polymorph $2^{\circ}$ & $\begin{array}{l}42.3 \\
+0.7\end{array}$ & $\begin{array}{l}47.8 \\
+0.8\end{array}$ & $\begin{array}{l}54.0 / 54.4 \\
+1.2 /+1.6\end{array}$ & $\begin{array}{l}69.9 / 70.4 \\
+0.3 /+0.8\end{array}$ & $\begin{array}{l}103.1 \\
+1.9\end{array}$ & $\begin{array}{l}168.6 \\
+0.2\end{array}$ \\
\hline $4 c^{d}$ & $\begin{array}{l}40.9 / 43.1 \\
-0.6 /+1.6\end{array}$ & $\begin{array}{l}51.8^{2} \\
+1.7\end{array}$ & $\begin{array}{l}55.1 / 56.8 \\
+1.3 /+3.0\end{array}$ & $\begin{array}{l}64.4 / 71.5 \\
-3.3 /+3.8\end{array}$ & $\begin{array}{l}100.5 / 104.9 \\
-0.9 /+3.5\end{array}$ & $\begin{array}{l}169.1^{\mathrm{a}} \\
+0.8\end{array}$ \\
\hline $6 b$ & $\begin{array}{l}39.2 \\
-1.4\end{array}$ & $\begin{array}{l}37.6 \\
-1.4\end{array}$ & $\begin{array}{l}56.8 \\
+2.9\end{array}$ & $\begin{array}{l}61.0 \\
-3.6\end{array}$ & $\begin{array}{l}102.2 \\
+1.6\end{array}$ & $\begin{array}{l}168.5 \\
-0.3\end{array}$ \\
\hline $6 \mathrm{c}$ & $\begin{array}{l}40.7 \\
-0.4\end{array}$ & $\begin{array}{l}40.1 \\
+0.9\end{array}$ & $\begin{array}{l}47.9 \\
-5.5\end{array}$ & $\begin{array}{l}64.4 \\
-1.7\end{array}$ & $\begin{array}{l}100.6 \\
-0.3\end{array}$ & $\begin{array}{l}170.9 \\
+1.8\end{array}$ \\
\hline
\end{tabular}

${ }^{a}$ Values corresponding to unresolved and/or broad signals.

${ }^{\mathrm{b}}$ Asymmetric doublet resulting from the quadrupolar moment of ${ }^{14} \mathrm{~N}$.

${ }^{c}$ Polymorphs 1 and 2 present the same solution spectrum.

${ }^{d}$ Compound $4 \mathrm{c}$ does not show any difference between the two chains in liquid NMR.

temperature in the solid and liquid states. The aim of these studies was to explore potential conformational changes by: (i) increasing the temperature in the solid state to enhance the flexibility of the ring and ultimately approach $\mathrm{C}_{7}-\mathrm{O}_{1-}$ $\mathrm{C}_{2}-\mathrm{C}_{3}, \mathrm{C}_{7}-\mathrm{O}_{1^{\prime}}-\mathrm{C}_{2^{\prime}}-\mathrm{C}_{3^{\prime}}$ trans conformations, (ii) decreasing the temperature in the liquid state to obtain a more constrained conformation. At $130{ }^{\circ} \mathrm{C}$ (maximum temperature technically available), no change was detected in the SSNMR spectra. In contrast, at $-80^{\circ} \mathrm{C}$ (minimum temperature available in $\mathrm{CD}_{2} \mathrm{Cl}_{2}$ ) ${ }^{\|}$all resonances, except the $\mathrm{CO}$ one, were shielded from about $0.6-1.0 \mathrm{ppm}$, in particular the $\mathrm{C}_{7}$ resonance $(\Delta \delta-0.8 \mathrm{ppm})$, shielding of which is consistent with possible gauche conformations at low temperature in the liquid state.

As noted for isomer 1c, the symmetry of isomer 1a is conserved in the solid state NMR spectrum. Compared with the liquid NMR spectrum, the deshielding of the CO carbon $(\Delta \delta+1.5 \mathrm{ppm})$ underlines again the presence of intermolecular $\mathrm{CO} \cdots \mathrm{HN}$ hydrogen bonds. Besides, the $\mathrm{C}_{7}$ shift variation $(\Delta \delta+2.5 \mathrm{ppm})$ indicates that no $\gamma$-gauche effect occurs in the solid state of this compound.

Concerning isomer $\mathbf{1 b}$, its ${ }^{13} \mathrm{C}$ SSNMR spectrum, which should exhibit two signals for each pair of identical groups, is characterized by 11 resolved lines: in fact, only the OMe, $\mathrm{C}_{3}, \mathrm{C}_{2}$ and $\mathrm{C}_{7}$ carbons are split. Intermolecular $\mathrm{CO} \cdots \mathrm{HN}$ hydrogen bonds are present once more as shown by the shift of the CO carbons $(\Delta \delta+1.4$ and $+1.0 \mathrm{ppm})$. Besides, as previously observed in the liquid NMR spectrum, the ${ }^{13} \mathrm{C}$ chemical shifts of chain 1 are nearly identical to those of 1a, and the $\delta$ values of chain $1^{\prime}$ are close to those of 1c (Table 6). These results indicate that a trans relationship between

\footnotetext{
"Low temperature liquid state experiments were run in $\mathrm{CD}_{2} \mathrm{Cl}_{2}$ instead of chlorofluorocarbons generally used for this purpose but in which the studied macrocycles were not soluble.
}

the 3-phenyl substituents and the OMe groups (as occurs in isomer a) implies trans or anti $\mathrm{C}_{7}-\mathrm{O}_{1}-\mathrm{C}_{2}-\mathrm{C}_{3}$ conformations, while a cis relationship (as occurs in isomer c) implies gauche $\mathrm{C}_{7^{\prime}}-\mathrm{O}_{1}-\mathrm{C}_{2}-\mathrm{C}_{3}$ conformations in the solid state in contrast with the anti conformations observed in the liquid phase.

Consequently if a positive difference in chemical shifts between the solid and liquid spectra $\left(\Delta \delta=\delta_{\text {solid }}-\delta_{\text {liquid }} \geq 0\right)$ is observed for the $C_{7}$ carbon, a trans conformation may be expected. In contrast, if $\Delta \delta<0$, a degree of conformational constraint, such as a gauche conformation, may be expected. The results obtained for the other compounds will be discussed on this basis.

The SSNMR spectrum of compound $2 \mathrm{c}$ which presents seven resonances for 14 carbons, indicates that the symmetry is also preserved in the solid phase (Table 6). The $C O$ downfield effect $(\Delta \delta=+1.9-+2.7 \mathrm{ppm})$ may be due, as seen above, to the presence of intermolecular $\mathrm{CO} \cdots$ $\mathrm{HN}$ hydrogen bonds. Besides, the $\mathrm{C}_{7}$ chemical shift variation $(\Delta \delta 0 \mathrm{ppm})$ is broadly indicative of a globally non-constrained conformation for $2 \mathrm{c}$ in the solid state. Thus, the simple presence of a methyl group in the $\mathrm{C}_{3}$ position appears insufficient to produce a constrained conformation.

The symmetry of the compound $\mathbf{3 c}$ in the solid phase is maintained: nine intense peaks are visible for 20 carbons ( $\mathrm{C}_{9}$ and one $\mathrm{OCH}_{3}$ being superimposed). Surprisingly, a polymorphic transformation occurs with time, while a such kinetic/thermodynamic evolution has never been observed for the other compounds. The thermodynamic polymorph spectrum shows a partial absence of symmetry as underlined by the splitting of $\mathrm{C}_{2}, \mathrm{C}_{9}, \mathrm{CH}_{3}$ and $\mathrm{OCH}_{3}$ carbons (SM). This asymmetry may be explained by a movement of the isobutyl side chain. It has to be noted that the two polymorphs give the same ${ }^{13} \mathrm{C}$ liquid state NMR spectrum. 
Moreover, the quasi absence of intermolecular hydrogen bonding $\left(\Delta \delta_{\mathrm{CO}}=+0.2-+0.6 \mathrm{ppm}\right)$ may be explained by the bulkiness of the two isobutyl substituents while the slight $C_{7}$ downfield shift $(\Delta \delta=+1.9-+2.3 \mathrm{ppm})$ agrees with a trans conformation, previously assigned by calculations.

The solid state spectrum of compound $\mathbf{4 c}$, compared with the liquid phase, shows an unsymmetrical conformation in regard to the $C_{2}$ axis. While the sites are conformationally averaged in solution to give one resonance, in the solid phase spectrum two resonances of nearly equal intensity are observed for each carbon, except for the $\mathrm{C}_{3}$ and $\mathrm{Ar}-\mathrm{CH}$ carbons, the peaks of which are broadened. The asymmetry could be due to different orientations or dynamic motions of the two phenyl rings, which could undergo a staccato-like rotation (or $\pi$-flip) ${ }^{36}$ and their non-equivalence could result from a lattice deformation corresponding to a minimum space occupation and a minimum repulsion. This observed asymmetry is consistent with the molecular modeling results that indicate for $4 \mathrm{c}$ : (i) different $\mathrm{N}_{4}-\mathrm{C}_{5}-\mathrm{C}_{6}-\mathrm{C}_{7}$ dihedral angles values between the two chains (Table 5), (ii) the presence of a single $\mathrm{NH}^{\cdots} \mathrm{O}_{1^{\prime}}$ intramolecular hydrogen bond up to conformer 5 (SM).

Finally, the spectra of the two achiral 3-unsubstitued macrocycles ( $6 b$ and $\mathbf{6 c}$ ) were recorded to investigate the influence of the methoxy groups on the 14-membered ring. For these two compounds, the symmetry is conserved in the solid state. The comparison for both compounds of liquid and solid state chemical shifts indicates that in the solid state: (i) intermolecular $\mathrm{CO} \cdots \mathrm{HN}$ hydrogen bonding occurs only in isomer $\mathbf{6 c}\left(\mathbf{6 c}: \Delta \delta_{\mathrm{CO}}+1.8 \mathrm{ppm} ; \mathbf{6 b}: \Delta \delta_{\mathrm{CO}} 0 \mathrm{ppm}\right)$, (ii) a trans conformation is conserved along the two bonds $\mathrm{C}_{7^{\prime}}-\mathrm{O}_{1}-\mathrm{C}_{2}-\mathrm{C}_{3}$, while a small $\gamma$-gauche effect is observed along the two bonds $\mathrm{C}_{6^{\prime}}-\mathrm{C}_{7^{\prime}}-\mathrm{O}_{1}-\mathrm{C}_{2}$ referring to the $\mathrm{C}_{2}$ and $\mathrm{C}_{6}$ chemical shift variations (Table 6).

Thus it appears from these results that the $\gamma$-gauche effect observed for $1 \mathrm{c}$ in the solid state is not dictated by the methoxy groups but is induced by the presence of the 3-phenyl substituent.

In summary, ${ }^{13} \mathrm{C}$ SS CPMAS NMR is a simple and useful tool for obtaining conformational data in the solid state. For compound 1c, the NMR results are consistent with those obtained by the X-ray analysis. More specifically, the NMR technique enabled us to show the presence of: (i) a symmetry in compounds $\mathbf{1 c - 3 c}, \mathbf{6 b}$ and $\mathbf{6 c}$, and an asymmetry in compound $4 \mathrm{c}$ in the solid state, (ii) intermolecular $\mathrm{CO} \cdots \mathrm{HN}$ hydrogen bonds for compounds $1 \mathrm{a}, \mathbf{1 c}-\mathbf{4 c}$ and $\mathbf{6 c}$, the strength of which decreases with the bulkiness of the substituents, (iii) strong gauche conformations for the two $\mathrm{C}_{7}-\mathrm{O}_{1}-\mathrm{C}_{2}-\mathrm{C}_{3}$ bonds in $1 \mathrm{c}$, and weaker gauche conformations for the two $\mathrm{C}_{6^{\prime}}-\mathrm{C}_{7^{\prime}}-\mathrm{O}_{1}-\mathrm{C}_{2}$ bonds in $\mathbf{6 b}$ and $\mathbf{6 c}$, (iv) polymorphic forms for compound $3 \mathrm{c}$, probably due to the high degree of freedom of the isobutyl side chain.

\section{Conclusion}

In the liquid state, the conformations of the 14-membered diketal dilactam macrocycles, which all show $\mathrm{gg}^{\prime}$ or $\mathrm{g}^{\prime} \mathrm{g}$ arrangements for $\mathrm{C}_{6}, \mathrm{C}_{6}$, seem to depend strongly on whether the molecules are chiral or achiral, and whether the OMe groups are in a cis or trans configuration. In achiral compounds, the more stable conformation has the two $\mathrm{NH}-\mathrm{CO}$ links perpendicular to the macrocyclic plane, with orientation either same (in $6 c, 7 c$ ) or opposite (in $6 b, 7 b$ ); this latter arrangement lends to $6 \mathbf{b}$ and $7 \mathbf{b}$ a rectangular [3434]-type structure with the four corners at $\mathrm{C}_{3}, \mathrm{C}_{3^{\prime}}, \mathrm{C}_{7}$, $\mathrm{C}_{7^{\prime}}$. In contrast, in the chiral compounds $\mathbf{1 - 5}$, the conformations are governed: (i) by the presence of one (in most isomers b) or two (in most isomers a and c) $\mathrm{N}_{4}-\mathrm{H} \cdots$ $\mathrm{O}_{1^{\prime}}, \mathrm{N}_{4^{\prime}}-\mathrm{H} \cdots \mathrm{O}_{1}$ intramolecular hydrogen bonds, which sets the amide function parallel to the macrocyclic plane, (ii) by the position of the OMe groups in regard to the 3-R substituents, (iii) by the nature of the 3-R substituent. Thus the structure $\operatorname{tg}^{\prime} \mathrm{ttg}^{\prime} \mathrm{gttg}^{\prime} \mathrm{ttg}^{\prime} \mathrm{gt}$ (Ic), which has no corner, is most frequently observed for $3,3^{\prime}$-monosubstituted compounds $\mathbf{1} \mathbf{c}-\mathbf{4 c}$, while no predominant structure appears for the corresponding isomers $\mathbf{a}$ and $\mathbf{b}$.

In the solid state, only slight changes in conformation seem to occur for the achiral compounds $\mathbf{6 b}$ and $\mathbf{6 c}$ in regard to the liquid state; they probably retain the more stable shape found in molecular modeling studies that is the NH-CO link perpendicular to the macrocyclic plane, with, however, in the present case, $\mathrm{NH} \cdots \mathrm{O}=\mathrm{C}$ intermolecular hydrogen bonds between successive sheets, $\mathrm{H}$ bonds underlined by a small $\gamma$ effect on the $\mathrm{C}_{2}$ and $\mathrm{C}_{6}$ carbons and, in $\mathbf{6 c}$, slight deshielding of the $\mathrm{CO}$ carbon. This orientation of the amide moieties is probably present in the solid state of chiral compounds $1 \mathrm{a}, \mathbf{1 b}, \mathbf{2 c - 4 c}$ with, however, the cohesive force of any intermolecular $\mathrm{H}$ bonds strongly weakened $(\mathbf{1 a}, \mathbf{1 b}$, $2 \mathrm{c})$ or cancelled $(3 \mathrm{c}, \mathbf{4 c})$ by the presence of 3 -R substituents. In contrast, in compound $\mathbf{1}$, the cohesion of the $\mathrm{NH} \cdots \mathrm{O}=\mathrm{C}$ intermolecular $\mathrm{H}$ bonds, revealed by the $\mathrm{X}$-ray analysis, is reinforced by a $\pi-\pi$ stacking effect between the phenyl groups, which adopt a position parallel to the macrocyclic plane and thus give to the molecule a constrained shape with an unusual gauche conformation along the two $\mathrm{C}_{7^{\prime}}-\mathrm{O}_{1}-\mathrm{C}_{2}-$ $\mathrm{C}_{3}$ bonds.

\section{Experimental}

\subsection{Synthesis}

The 14-membered ring diketal dilactam syntheses were previously reported. ${ }^{1}$

\subsection{Liquid NMR}

Proton and carbon NMR spectra were recorded in deuteriochloroform solutions using a Bruker AC 400 spectrometer $\left({ }^{1} \mathrm{H}: 400 \mathrm{MHz} ;{ }^{13} \mathrm{C}: 100 \mathrm{MHz}\right)$, equipped with a DUAL ${ }^{1} \mathrm{H} /{ }^{13} \mathrm{C}$ probe, at $303 \mathrm{~K}$. Chemical shifts are given in parts per million (ppm) and referenced to chloroform $(\delta=$ $7.27 \mathrm{ppm}$ for ${ }^{1} \mathrm{H}$ and $77.1 \mathrm{ppm}$ for ${ }^{13} \mathrm{C}$ ) as internal standard.

The NOE measurements were made on a Bruker spectrometer, model DSX 300, equipped with a double resonance probe, at $303 \mathrm{~K}$ with $10 \mathrm{mM} \mathrm{CDCl}_{3}$ solutions. Samples were degassed by bubbling dry argon through the solution in the 
NMR tube for $30 \mathrm{~min}$. NOE difference spectra were recorded after presaturation of the signal to irradiate using the 'NOEmult' pulse sequence. The following conditions were used: proton relaxation delay $1 \mathrm{~s}$, irradiation period $2.5 \mathrm{~s}$ ( 50 presaturation cycles of $50 \mathrm{~ms}$ ), total measuring time $7 \mathrm{~s}$. Each FID corresponds to the average of 64 acquisitions and the NOE difference spectra to the average of 8 FID.

\subsection{Molecular modeling}

The MACROMODEL molecular modeling program (version 7.0) developed by Still and co-workers ${ }^{38}$ was used to determined the global minimum conformations of the macrocyclic diketals dilactams. The AMBER force field ${ }^{39}$ implemented in the program and well-suited to the study of compounds incorporating amide functions was chosen. The method known as Monte-Carlo Multiple Minimum Search (MCMM) was applied. The starting structure was the previously determined XR structure of the macrocycle 1c. ${ }^{\text {a }}$ All other structures were written from the 1c minimum conformation. A minimum of 5000 conformations were minimized for every compound. Detection conditions for hydrogen bonds: interatomic distances $d<2.5 \AA$, angles: $\mathrm{N}-\mathrm{H} \cdots \mathrm{O}<90^{\circ}$ and $\mathrm{H} \cdots \mathrm{O}-\mathrm{R}$ $<60^{\circ}$.

\subsection{Solid state NMR}

The high-resolution ${ }^{13} \mathrm{C}$ solid state spectra were recorded at $75.46 \mathrm{MHz}$ on a Bruker Avance DSX-300 spectrometer with a double bearing magic angle spinning (MAS) probehead. The samples were packed in $4 \mathrm{~mm}$ zirconia rotors fitted with Kel-F caps, and when the amount of macrocycle was not sufficient, the sample volume was reduced in the center of the rotor using a Teflon insert. The samples were spun at the magic angle with a speed of $10 \mathrm{kHz}$ at ambient temperature. A ramped cross polarization (RACP) from protons to carbon was carried out at a proton nutation frequency of $70 \mathrm{kHz}$ over a contact time of $1.5 \mathrm{~ms}$ and a recycle delay of $3 \mathrm{~s}$. The proton $\mathrm{CW}$ decoupling field strength was $68 \mathrm{kHz}$, and when necessary a TPPM decoupling ${ }^{40}$ with a ${ }^{1} \mathrm{H}$ nutation frequency of $70 \mathrm{kHz}$, a pulse length of $6.0 \mu \mathrm{s}$ and a phase shift of $15^{\circ}$ was used to resolve the asymmetric doublet due to the large ${ }^{14} \mathrm{~N}$ quadrupolar coupling. Dipolar dephased spectra were obtained by turning off the ${ }^{1} \mathrm{H}$ decoupling for a short time after the cross-polarization pulse. Also, to suppress the movable methyl groups, the delay was set between 25 and $150 \mu$ s depending on the structure. Free induction decays (FID) were digitized into $6 \mathrm{~K}$ data points and Fouriertransformed after applying $5 \mathrm{~Hz}$ exponential line broadening. The number of transients (200-4096) was fitted to reach optimal signal-to-noise ratios. ${ }^{13} \mathrm{C}$ chemical shifts were measured relative to an external reference (carbonyl of glycine: $176.03 \mathrm{ppm}$, Aldrich), set carefully before each spectrum.

\section{Supplementary data}

Supplementary data associated with this article can be found, in the online version, at doi:10.1016/j.tet.2005.03. 073

Tables of: (1) Relative energy ( $\mathrm{kJ} \mathrm{mol}^{-1}$ ) of the 10 first conformers of compounds 1-7; (2) $\mathrm{H}_{3}-\mathrm{C}_{3}-\mathrm{C}_{2}-\mathrm{H}_{2}$ and $\mathrm{H}_{7}-$ $\mathrm{C}_{7}-\mathrm{C}_{6}-\mathrm{H}_{6}$ dihedral angles; (3) Interatomic distances between the $\mathrm{H}_{6}$ hydrogens and the OMe oxygens; (4) Interatomic distances between the $\mathrm{NH}$ hydrogens and the endocyclic acetalic oxygens.

Solid state ${ }^{13} \mathrm{C}$ NMR chemical shifts of macrocycles 1a-c, $2 c-4 c, 6 b-c$ and spectra of $1 a-c$.

\section{References and notes}

1. (a) Dugat, D.; Chiaroni, A.; Riche, C.; Royer, J.; Husson, H.-P. Tetrahedron Lett. 1997, 38, 5801-5804. (b) Valade, A.-G.; Dugat, D.; Jeminet, G.; Royer, J.; Husson, H.-P. Eur. J. Org. Chem. 2001, 11, 2041-2053.

2. Pointud, Y.; Valade, A.-G.; Pointon, C.; Dugat, D.; Jeminet, G.; Beltran, J.-L. Supramol. Chem. 2003, 15, 261-269.

3. (a) Dale, J. J. Chem. Soc. 1963, 93-111. (b) Dale, J. Angew. Chem., Int. Ed. Engl. 1966, 5, 1000-1021.

4. (a) Dale, J. Acta Chem. Scand. 1973, 27, 1115-1129. (b) Dale, J. Acta Chem. Scand. 1973, 27, 1130-1148.

5. (a) Anet, F. A. L.; Cheng, A. K.; Wagner, J. J. J. Am. Chem. Soc. 1972, 94, 9250-9252. (b) Anet, F. A. L.; Cheng, A. K. J. Am. Chem. Soc. 1975, 74, 2420-2424.

6. Groth, P. Acta Chem. Scand. 1976, A30, 155-156.

7. Drotloff, H.; Rotter, H.; Emeis, D.; Möller, M. J. Am. Chem. Soc. 1987, 109, 7797-7803.

8. Saunders, M. J. Am. Chem. Soc. 1987, 109, 3150-3152.

9. Shannon, V. L.; Strauss, H. L.; Snyder, R. G.; Elliger, C. A.; Mattice, W. L. J. Am. Chem. Soc. 1989, 111, 1948-1958.

10. Dunitz, J. D. Perspectives in Structural Chemistry; Wiley: New-York, 1968; (a) p 18; (b) p 20.

11. Borgen, G.; Dale, J. Chem. Commun. 1970, 1340-1342.

12. Dale, J. Acta Chem. Scand. 1973, 27, 1149-1158.

13. Clyne, D. S.; Weiler, L. Tetrahedron 2000, 56, 1281-1297.

14. Bassi, I. W.; Scordamaglia, R.; Fiore, L. J. Chem. Soc., Perkin Trans 2 1972, 1726-1729.

15. Dunitz, J. D.; Meyer, E. F., Jr. Helv. Chim. Acta 1965, 48, 1441-1449.

16. Brown, C. J. J. Chem. Soc. (C) 1966, 1108-1112.

17. Anet, F. A. L.; Cheng, A. K.; Krane, J. J. Am. Chem. Soc. 1973, $95,7877-7878$.

18. Groth, P. Acta Chem. Scand. 1975, A 29, 374-380.

19. Borgen, G.; Dale, J. Acta Chem. Scand. 1972, 26, 1799-1804.

20. Groth, P. Acta Chem. Scand. 1979, A 33, 503-513.

21. Wiberg, K. B.; Waldron, R. F.; Schulte, G.; Saunders, M. J. Am. Chem. Soc. 1991, 113, 971-977.

22. Borgen, G.; Dale, J.; Rise, F.; Gundersen, L.-L. Magn. Reson. Chem. 1996, 34, 289-292.

23. Dale, J. Top. Stereochem. 1976, 9, 199-269.

24. Borgen, G.; Dale, J.; Gundersen, L.-L.; Krivokapic, A.; Rise, F.; Overas, A. T. Acta Chem. Scand. 1998, 52, 1110-1115.

25. Naruse, N.; Konishi, M.; Oki, T.; Inouye, Y.; Kakisawa, H. J. Antibiot. 1991, 44, 756-761.

26. Hedge, V. R.; Patel, M. G.; Gullo, V. P.; Ganguly, A. K.; Sarre, 
O.; Puar, M. S.; McPhall, A. T. J. Am. Chem. Soc. 1990, 112, 6403-6405.

27. Northolt, M. G.; Alexander, L. E. Acta Crystallogr. 1971, B27, 523-531.

28. Dale, J.; Coulon, R. J. Chem. Soc. 1964, 182-187.

29. Laws, D. D.; Bitter, H.-M.L.; Jerschow, A. Angew Chem., Int. Ed. 2002, 41, 3096-3129.

30. Uhrin, D.; Liptaj, T. J. Magn. Reson. 1989, 8, 82-91.

31. Morzycki, J. W.; Wawer, I.; Gryszkiewicz, A.; Maj, J.; Siergiejczyk, L.; Zaworska, A. Steroids 2002, 67, 621-626.

32. Buchanan, G. W.; Kirby, R. A.; Charland, J. P. J. Am. Chem. Soc. 1988, 110, 2477-2483.

33. Munowitz, M. G.; Griffin, R. G.; Bodenhausen, G.; Huang, T. H. J. Am. Chem. Soc. 1981, 103, 2529-2533.

34. Hughes, C. E.; Pratima, R.; Karlsson, T.; Levitt, M. H. J. Magn. Reson. 2002, 159, 25-35.
35. Buchanan, G. W.; Rastegar, M. F. Solid State Nucl. Magn. Reson. 2001, 20, 137-144.

36. Glaser, R.; Novoselsky, A.; Shiftan, D.; Drouin, M. J. Org. Chem. 2000, 65, 6345-6353.

37. Scheler, U. In Solid State NMR Spectroscopy: Principles and Applications; Duer, M. J., Ed.; Blackwell Science: Oxford, 2002; pp 485-509.

38. Mohamadi, F.; Richards, N. G. J.; Guida, W. C.; Liskamp, R.; Lipton, M.; Caufield, C.; Chang, G.; Hendrickson, T.; Still, W. C. J. Comput. Chem. 1990, 11, 440-467.

39. Weiner, S. J.; Kollman, P. A.; Nguyen, D. T.; Case, D. A. J. Comput. Chem. 1986, 7, 230-252.

40. Bennett, A. E.; Rienstra, C. M.; Auger, M.; Lakshmi, K. V.; Griffin, R. G. J. Chem. Phys. 1995, 103, 6951-6957. 